\title{
On the Fine-Scale Topography Regulating Changes in Atmospheric Hydrological Cycle and Extreme Rainfall over West Africa in a Regional Climate Model Projections
}

\author{
M. B. Sylla, ${ }^{1,2}$ A. T. Gaye, ${ }^{1}$ and G. S. Jenkins ${ }^{3}$ \\ ${ }^{1}$ Laboratory for Atmospheric Physics-Simeon Fongang (LPASF), Polytechnic School, Cheikh Anta Diop University, \\ P.O. Box 5085, Dakar-Fann, Senegal \\ ${ }^{2}$ Earth System Physics Section, International Centre for Theoretical Physics (ICTP), 34151 Trieste, Italy \\ ${ }^{3}$ Howard University Program in Atmospheric Sciences, Department of Physics and Astronomy, Washington, DC 20059, USA
}

Correspondence should be addressed to M. B. Sylla, syllabamba@yahoo.fr

Received 27 April 2011; Revised 27 October 2011; Accepted 5 November 2011

Academic Editor: Alessandra Giannini

Copyright ( 2012 M. B. Sylla et al. This is an open access article distributed under the Creative Commons Attribution License, which permits unrestricted use, distribution, and reproduction in any medium, provided the original work is properly cited.

\begin{abstract}
The ICTP-RegCM3 is used to downscale at $40 \mathrm{~km}$ projections from ECHAM5 over West Africa during the mid and late $21 \mathrm{st}$ Century. The results show that while ECHAM5 projects wetter climate along the Gulf of Guinea and drier conditions along the Sahel, RegCM3 produces contrasting changes for low-elevation (negative) and high-elevation (positive) terrains more marked during the second period. These wetter conditions in the uplands result from an intensification of the atmospheric hydrological cycle arising as a consequence of more frequent and denser rainy days and leading to larger intensity and more extreme events. Examination of the large-scale dynamics reveal that these conditions are mostly driven by increased low-level moisture convergence which produces elevated vertical motion above Cameroun's mountainous areas favoring more atmospheric instability, moisture, and rainfall. This regulation of climate change signal by high-elevation terrains is feasible only in RegCM3 as the driving ECHAM5 is smoothing along all the Gulf of Guinea. This consolidates the need to use regional climate model to investigate the regional and local response of the hydrological cycle, the daily rainfall and extreme events to the increasing anthropogenic GHG warming for suitable impact studies specifically over region with complex topography such as West Africa.
\end{abstract}

\section{Introduction}

Climate change information is needed at the regional and local scales over West Africa for impacts assessment and development of suitable mitigation and adaptation plans. To date, most of the regional changes due to increasing anthropogenic greenhouse gas (GHG) concentrations are derived from coupled global climate models (GCMs). Kamga et al. [1] found that the Sahel region is wetter in the 21st century in association with increased atmospheric moisture. In contrast, Hulme et al. [2] projected large reduction of precipitation over the Sahel. Recently, Giannini et al. [3] stated that there is no agreement among GCMs about future changes of precipitation over West Africa $[4,5]$. This highlights arising difficulties while simulating and analyzing the West African climate with GCMs. The reasons may be related to the existence of mesoscale convection systems (MSCs), coastlines, marked gradient of vegetation, and complex topography forcing precipitation over the region.

To bridge the gap between these fine-scale processes and the resolution of climate models, regional climate modeling [6] is critical for West Africa. Regional climate models take the large-scale atmospheric circulation supplied by either reanalysis or atmosphere-ocean coupled global climate model (AOGCM) data at the lateral boundaries, resolve the complex topography, the land-sea contrast, the surface heterogeneities, and the detailed description of physical processes, and generate realistic high-resolution information coherent with the driving field. As a result, RCM is widely used to provide regional and local climate change information [7-14] but also to conduct process studies [1520]. 
The performance of the International Centre for Theoretical Physics (ICTP) regional climate model (RegCM3; [21]) in simulating the present-day West African climate and the projected Sahel rainfall was analyzed by Sylla et al. [22, 23], respectively. RegCM3 was driven at the lateral boundaries by the European Center/Hamburg 5 (ECHAM5 [24]) coupled to the Max Planck Institute ocean model (MPIOM; [25]) for the periods 1981-2000 and 2081-2100. Sylla et al. [22] found that RegCM3 was able to realistically reproduce the spatial distributions of rainfall, temperature, and the dynamics of the different monsoon circulation features. RegCM3 also exhibited some dry but lower (compared to ECHAM5/MPIOM hereafter referred to as ECHAM5) bias mostly over orographic regions of Guinea Highlands and Cameroun Mountains with respect to the Climatic Research Unit (CRU) observations. However, we should emphasize that very high resolution of observational datasets is not fully available over these regions with steep topography making it difficult to detect related local precipitation patterns and better assess added value [26]. In any case, the present-day regional bias is of minor importance in determining the simulated regional change [27]. In multidecal simulations carried out under increasing GHG forcing (A1B scenario [28]), Sylla et al. [23] showed that the future scenario simulation produces drier conditions over the Sahel and wetter conditions over orographic areas. In-depth analysis of the monsoon dynamics revealed that the changes in the circulation features are characteristics of dry periods over the Sahel and are similar to the conditions found in the late twentieth century observed drought in the region. We should specify that Sylla et al.'s paper [23] was only based on RegCM3 results and mostly focused on verifying how the projected rainfall over the Sahel was related to future monsoon circulation changes. Little interest was however given to the complex terrains.

In this paper, we extend the analysis of Sylla et al. [23] over the Guinea Coast mountainous areas and discuss the possible role of topography in shaping the changes in atmospheric water cycle and extreme rainfall by examining the differences between the projected patterns derived from RegCM3 and the driving ECHAM5.

In fact, mountain ecosystems over West Africa are often fertile but densely populated and provide resources that are strongly coveted by many actors. They are mostly very limited in spatial extension and are subject to rapid changes in climate. Many upland management issues, such as flooding and drought, are highly sensitive to climate change. Climatic variables needed for vulnerability assessment must be projected at regional or local scales, and this requires an understanding of potential future changes over complex terrains. None of the GCMs climate change scenario studies done over the region have identified a particular fine-scale signal over these areas, and most of them are smoothing. Although increasing anthropogenic GHG concentration is likely going to impact the global climate, the response of local complex terrains forcing such as Guinea Highlands and Cameroon Mountains over West Africa in terms of mean hydrological cycle and extreme events is not yet fully addressed.
To investigate this issue, we used RegCM3 to construct projections of climate over West Africa under the IPCC midrange GHG emission scenario A1B [28]. The objective of this paper is not however to provide more reliable scenarios over the region but to examine the local response of highelevation terrains with respect to the low-elevation regions to the climate change signal, with emphasis on the atmospheric hydrological cycle and extreme events, in a regional climate model compared to the driving global climate model.

We describe the models and experiments in Section 2, discuss the results in Section 3, and summarize and conclude in Section 4.

\section{Description of Numerical Experiments}

The ICTP RegCM3 [21, 29, 30] is used to downscale future scenarios from ECHAM5 [24] over West Africa. RegCM3 is a primitive equation, sigma vertical coordinate, and regional climate model based on the hydrostatic version of the dynamical core of NCAR/PSU's mesoscale meteorological model MM5 [31]. Radiation is represented by the CCM3 parameterization of Kiehl et al. [32], and the planetary boundary scheme is represented by Holtslag et al. [33] parameterization. Interactions between the land surface and the atmosphere are described using the biosphereatmosphere transfer scheme (BATS1E; [34]). Zeng et al.'s scheme [35] is used to represent fluxes from oceans. Convective precipitation is represented based on Grell et al.'s scheme [31] applying the Fritsch and Chappell [36] closure assumption. Resolvable precipitation processes are treated with the subgrid explicit moisture scheme (SUBEX) of Pal et al. [37] which is a physically based parameterization that includes variation at the subgrid scale of clouds, cloud water accretion, and evaporation of raindrops.

ECHAM5 [24], this fifth generation atmospheric general circulation model developed at the Max Planck Institute for Meteorology (MPIM), is the most recent version in a series of ECHAM models evolving originally from the spectral weather prediction model of the European Centre for Medium Range Weather Forecasts (ECMWF). The ensemble member used in this experiment has a T63 horizontal spectral resolution $\left(1.9^{\circ} \times 1.9^{\circ}\right.$ approximately $)$ and 19 vertical levels, with the top extending to $10 \mathrm{hPa}$. ECHAM5 is coupled to the MPIOM [25] ocean model to provide 6-hourly data of sea surface temperature for the whole period of integration.

The domain and topography from RegCM3 and ECHAM5 are displayed in Figure 1(a) and are the same as those used in Sylla et al.'s paper [22, 23]. The topography exhibits some complex terrains (e.g., Figure 1(a)): Guinea Highlands $\left(\sim 10^{\circ} \mathrm{N} ; 13^{\circ} \mathrm{W}\right)$, Cameroon Mountain $\left(\sim 6^{\circ} \mathrm{N}\right.$; $\left.12^{\circ} \mathrm{E}\right)$, and Jos Plateau $\left(\sim 10^{\circ} \mathrm{N} ; 7.5^{\circ} \mathrm{E}\right)$. We should note that ECHAM5 is often giving lower altitudes of mountains compared to RegCM3, and these differences may affect the local response to the increasing GHG concentration. RegCM3 has been integrated over this domain for two future time slices of 20 years long each at a spatial resolution of $40 \mathrm{~km}$. The first period coincides with the early 21 st century (2031-2050), and the second one with the last two decades 


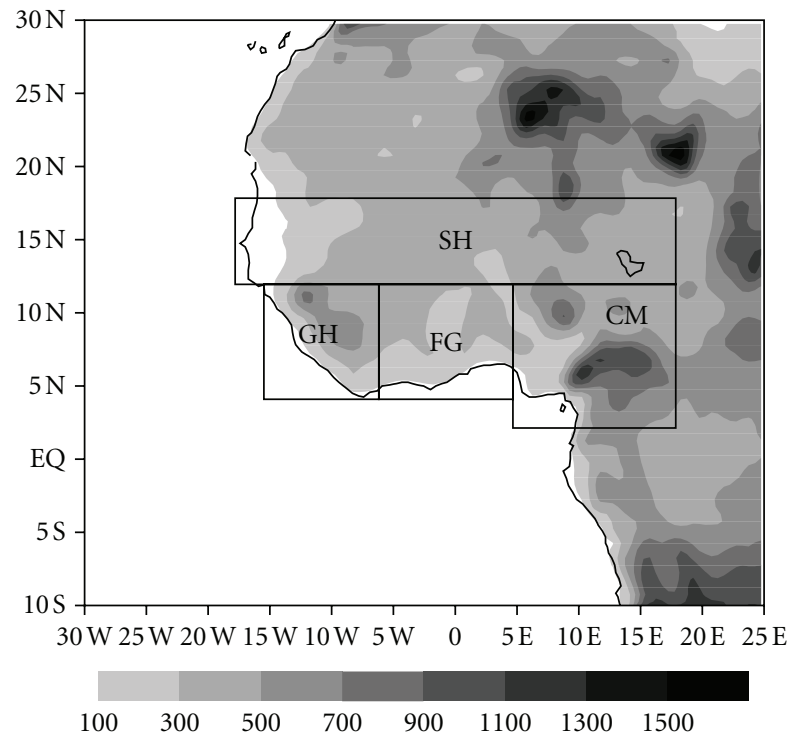

(a) RegCM3 topography

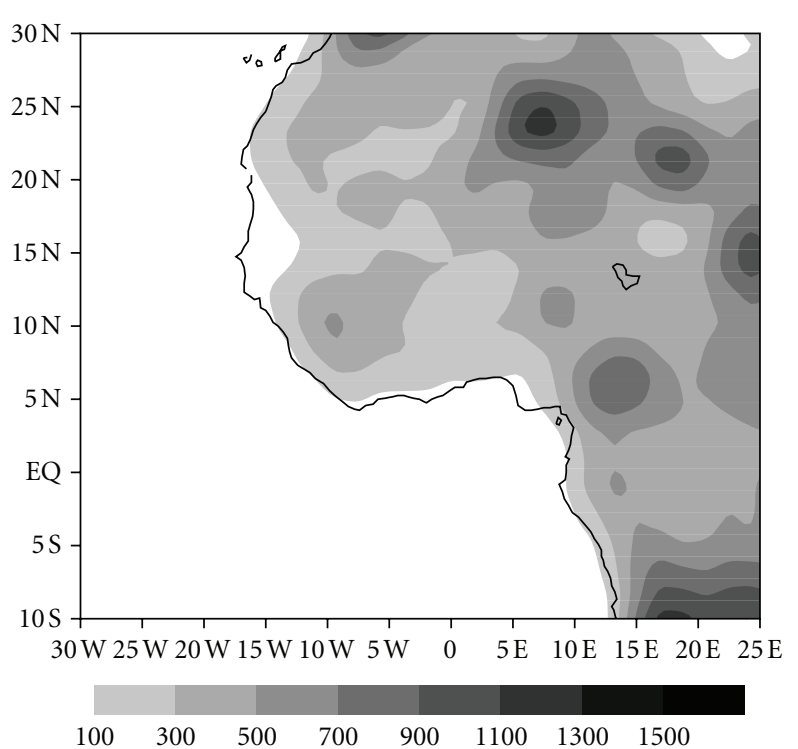

(b) ECHAM5 topography

FIGURE 1: Interior domain, topography, and subregions. SH stands for Sahel; GH: Guinea Highlands; FG: Flatter (low-elevation terrains) of Gulf of Guinea; CM: Cameroun Mountains.

of the 21st century (2081-2100). The midrange IPCC A1B emission scenario [28] is considered in these experiments.

The analysis is carried out by differentiating the future time periods and the present-day climate by considering only the peak monsoon season JJA (June-July-August). We mostly emphasize changes in the hydrological cycle and in the characteristics of daily rainfall and extreme events. Table 1 summarizes the climate indices selected to characterize the rainfall events and extremes, while the atmospheric water budget equation is given by the equation below:

$$
E-P=\frac{\partial w}{\partial t}+\nabla \cdot \frac{1}{g} \int q V d p
$$

where $E$ represents the evaporation, $P$ is the precipitation, $w=(1 / g) \int q d p$ is the precipitable water, $q$ is the specific humidity, and $V$ is the velocity vector. Equation (1) indicates that the difference between evaporation and precipitation is balanced by the local rate of water vapour change in the atmospheric column and by the vertically integrated moisture flux divergence. The first right-hand side term is negligible for monthly or seasonal time scales, while the second term is particularly important for the West African Monsoon where the divergent wind component, mainly depending on regional forcing, is dominant [38]. This divergent term mostly provides information about the atmospheric humidity content, and therefore, its change can be substituted by the change in precipitable water represented as the vertical integration of specific humidity. As a consequence, we analyse changes in mean precipitation and in the elements of the hydrological cycle as well as in the second-order daily statistics such as frequency and density of rainy events, intensity of wet days, and extreme rainfall for each time period and for both RegCM3 and ECHAM5. In particular, we discuss how the high-elevation terrains are
TABLE 1: Definition of indices.

\begin{tabular}{|c|c|}
\hline Indices & Definitions \\
\hline Frequency & $\begin{array}{l}\text { Maximum number of days with precipitation } \\
>1 \mathrm{~mm}\end{array}$ \\
\hline Intensity & Precipitation intensity due to the wet days only \\
\hline 95th percentile & Only $5 \%$ of the data are above this value \\
\hline $\begin{array}{l}\text { Highest one-day } \\
\text { precipitation }\end{array}$ & Intensity of the highest daily rainfall event \\
\hline
\end{tabular}

shaping the regional response of the climate change signal to increasing GHG warming over West Africa by comparing RegCM3 and ECHAM5 projections.

\section{Results and Discussions}

3.1. Mean Changes in the Atmospheric Water Cycle Components. Precipitation changes produced by ECHAM5 and RegCM3 for the early and late 21st century are shown in Figures 2(a)-2(d), respectively. Shaded areas are where changes are significant at $90 \%$ of confidence level. During the first time period, ECHAM5 situates decrease of rainfall of about $5-40 \%$ of the present-day values in the western Sahel region and increase in the western part of the Gulf of Guinea and eastern Sahel of about 5-10\%. RegCM3 provides similar changes but limits the dry conditions over the coastal countries of the Sahel (Senegal) and extends the wetter conditions to the central Sahel and down to the Cameroun Mountains. During the second future time period, ECHAM5 exhibits a dipole pattern consisting of amplified dry conditions, up to $60 \%$ of the present-day values, over the Sahel and wetter conditions of about $10-40 \%$ south of $10^{\circ} \mathrm{N}$ along the Guinea Coast. This broad pattern is generally replicated 


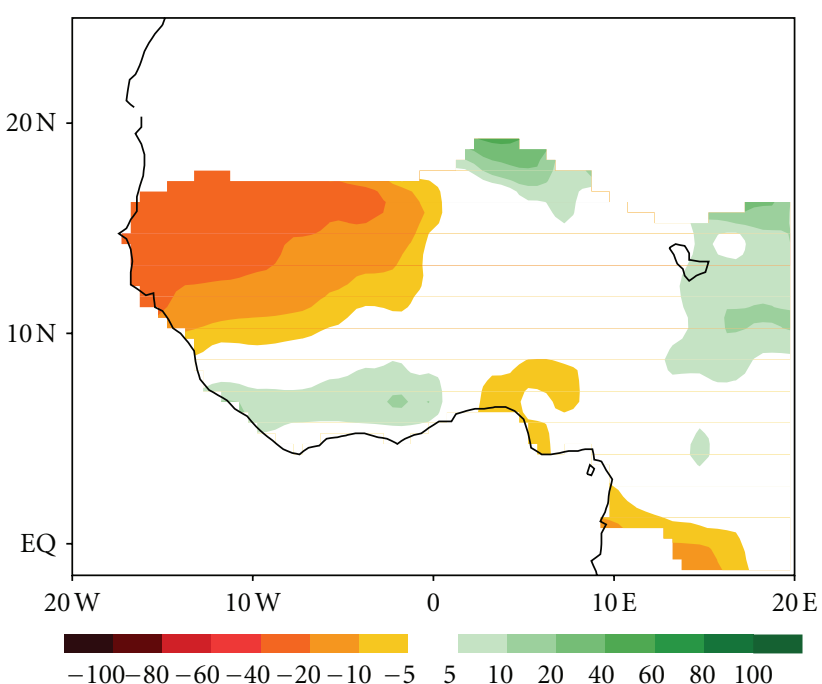

(a) ECHAM5 (2031-2050) minus (1981-2000)

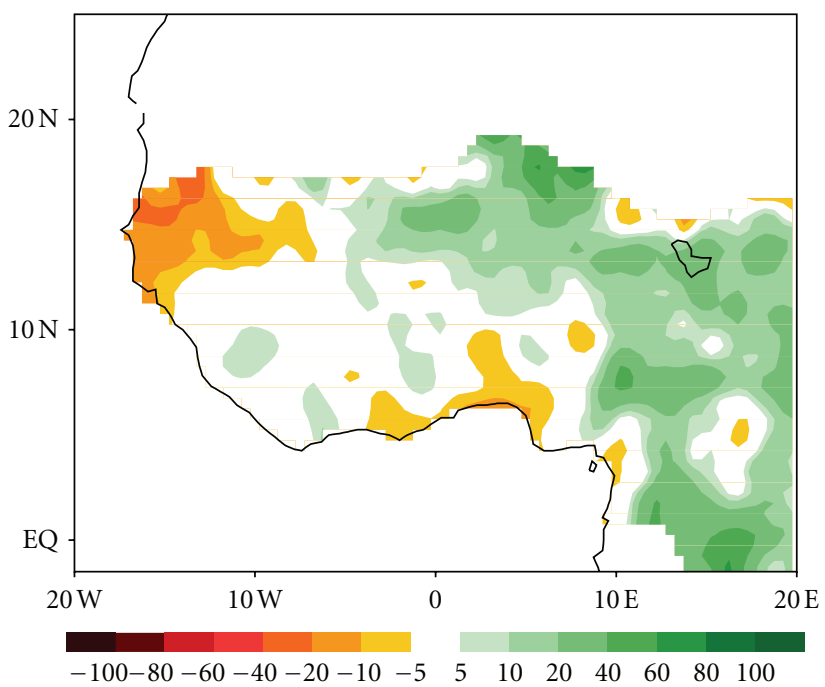

(c) RegCM3 (2031-2050) minus (1981-2000)

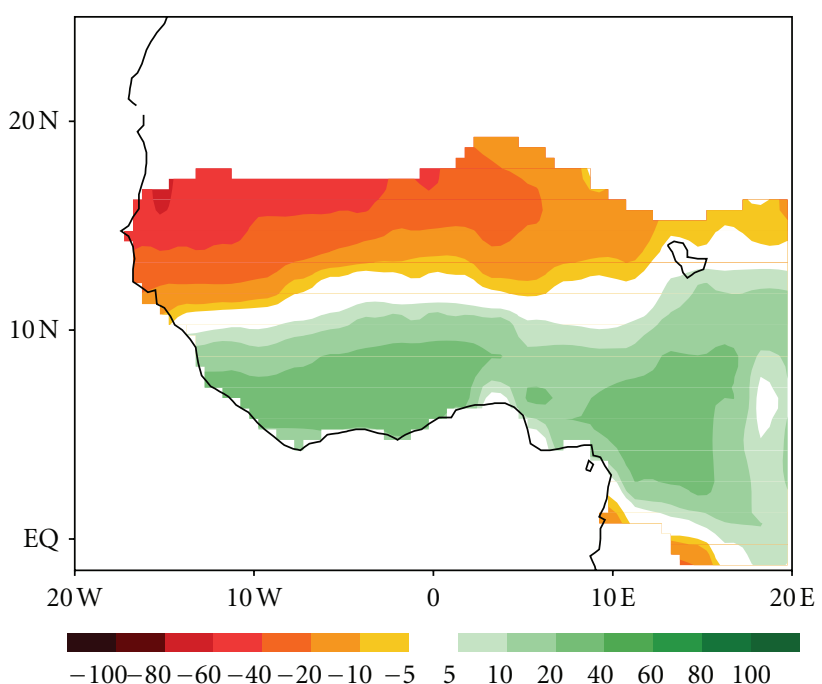

(b) ECHAM5 (2081-2100) minus (1981-2000)

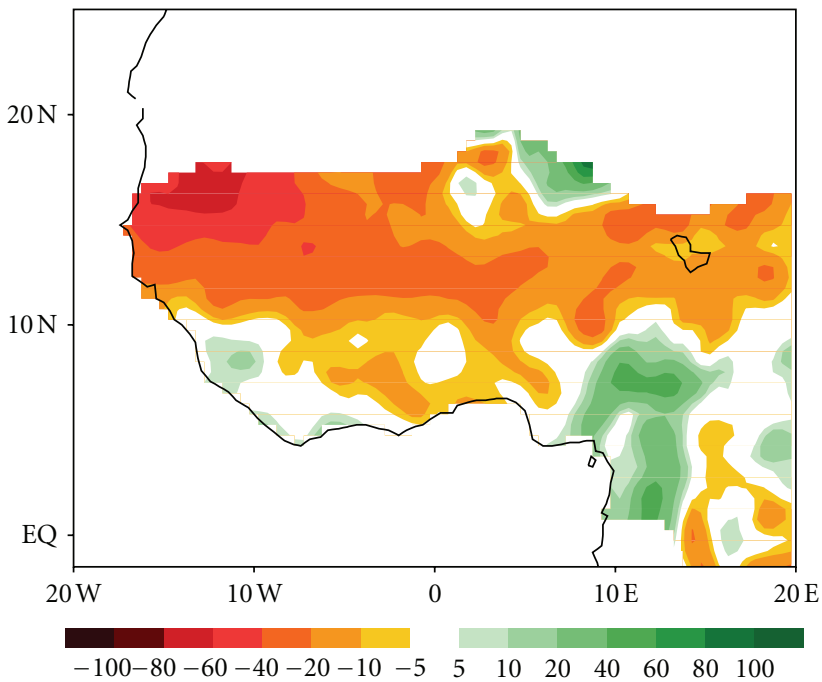

(d) RegCM3 (2081-2100) minus (1981-2000)

FIGURE 2: Summer (June-August) difference (A1B minus reference) in mean precipitation from ECHAM5 (upper) and RegCM3 (lower) during the early (left) and the late (right) 21 st century. Units are expressed as the percentage of present-day value, and only areas where changes are statistically significant at the $90 \%$ level are shaded.

by RegCM3 but at a finer resolution. In fact, the negative rainfall changes are substantially larger and more extended over the entire West Africa except around orographic regions of Cameroun and, to a lesser extent, around the peak of Guinea Highlands. In these complex terrains, the regional model projects increase of summer rainfall of about $10-60 \%$ following the shape of the mountains. We should note that these wetter conditions are found over the complex terrains where temperature changes are smaller (e.g., [23]) indicating a significant role of cloud cover. Although it is smoothing the signal along the entire Guinea Coast, the global model is able to simulate positive changes in the complex terrains and negative changes over the Sahel, hence confirming the strong influence of the boundary forcing on the regional climate model simulation [6]. Overall, while ECHAM5 projects wetter Gulf of Guinea and drier Sahel, the RegCM3 is able to offer finer spatial details and opposite sign of changes from the low-elevation terrains (negative changes) to the uplands (positive changes) indicating a substantial sensitivity of the West African regional climate to the regional and local forcing and processes such as land surface heterogeneities and complex terrains. The way these processes modulate the large-scale climate change signal is discussed in Section 3.4.

Another important parameter of the atmospheric water cycle is the surface evaporation. Change in surface evaporation, shown in Figures 3(a)-3(d), mostly mimics those of the mean rainfall. In fact, during the early 21st century, both global and regional climate models display lower 


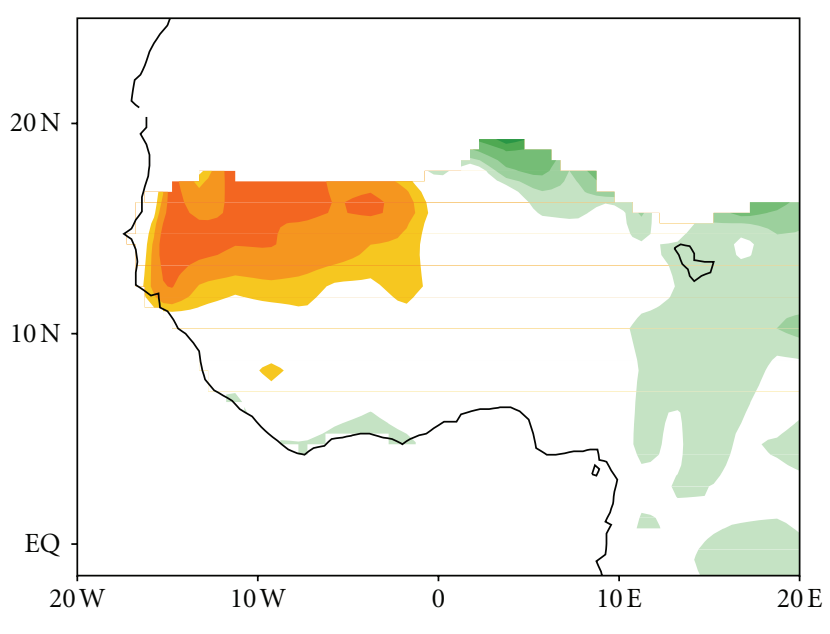

$-100-80-60-40-20-10-5 \quad 5 \quad 10 \quad 20 \quad 40 \quad 60 \quad 80 \quad 100$

(a) ECHAM5 (2031-2050) minus (1981-2000)

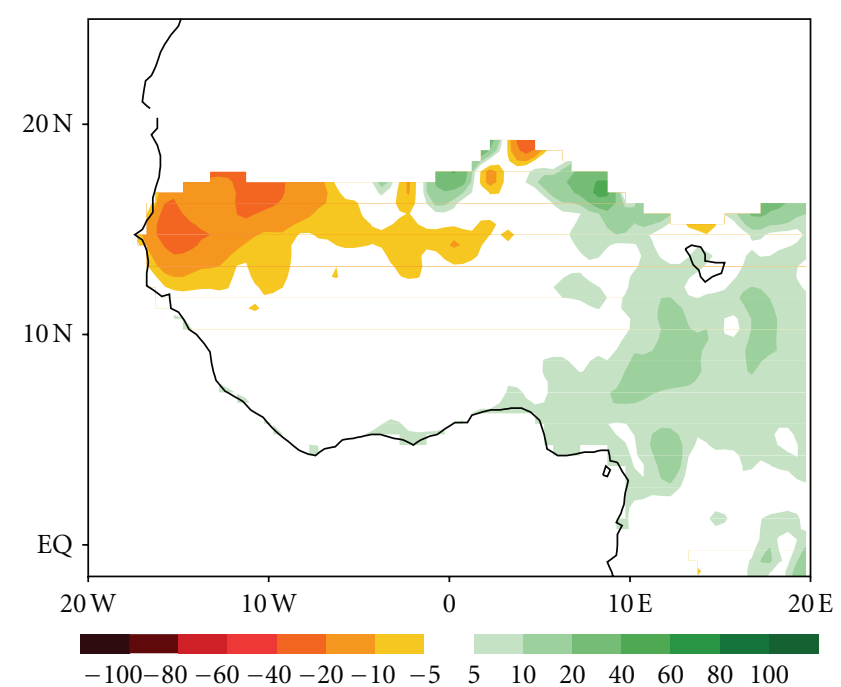

(c) RegCM3 (2031-2050) minus (1981-2000)

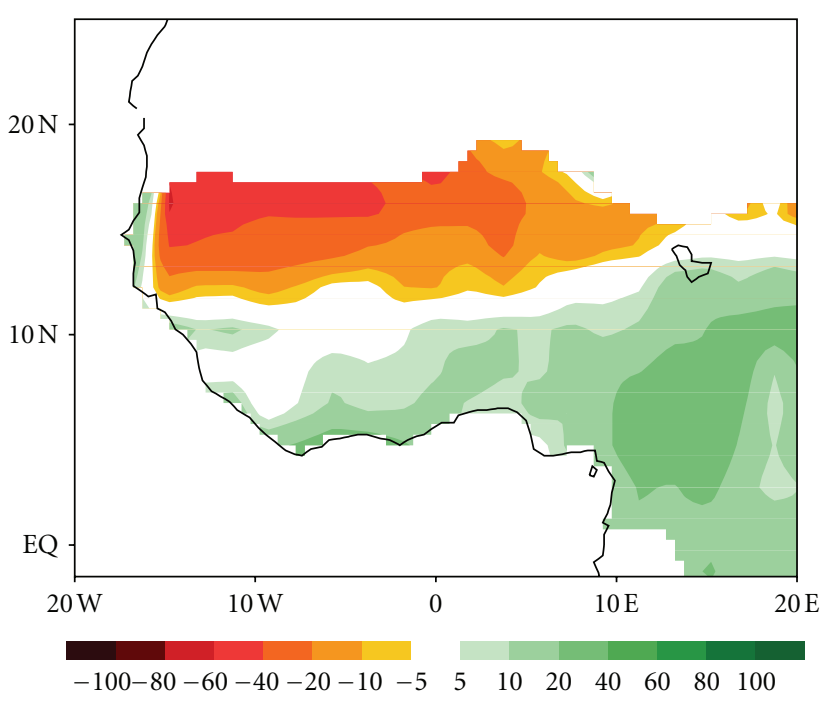

(b) ECHAM5 (2081-2100) minus (1981-2000)

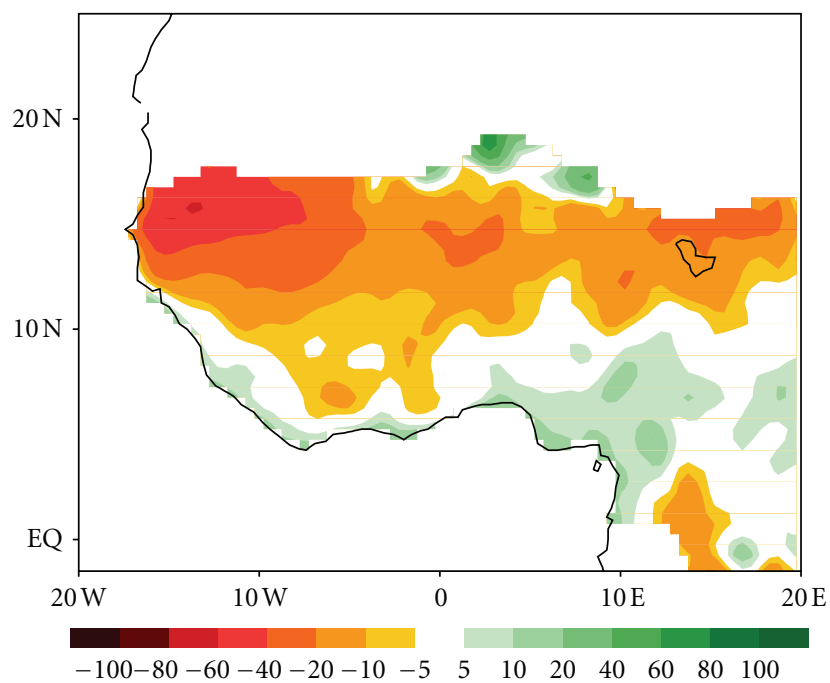

(d) RegCM3 (2081-2100) minus (1981-2000)

Figure 3: The same as Figure 2 but for evaporation.

evaporation in the western Sahel and larger evaporation in the eastern part of West Africa including the Cameroun complex terrains. As for the mean rainfall during the second future time period, ECHAM5 provides positive changes along the Guinea Coast and negative changes in regions above, while the higher resolution RegCM3 exhibits larger amount of evaporation only over the peak of Cameroun Mountains. In these complex terrains, the total soil moisture content does not exhibit significant changes (Figures 4(a)$4(d))$. In contrast, in the low elevation terrains where rainfall and evaporation changes are negative, the total soil moisture content is lower in the future time periods suggesting that surface evaporation change is driven to a large extent by precipitation change.

In opposite to the mean changes of rainfall and evaporation which exhibit a dipole pattern, the precipitable water (vertical integration of specific humidity), shown in Figures 5(a)-5(d) for ECHAM5 and RegCM3, undergoes a general increase more marked during the second future time period with the more significant increase occurring along the Cameroun Mountains peak (more than 30\%) indicating a stronger water vapour feedback. However, this general increase of precipitable water does not lead to future increased rainfall over the Sahel because of an African easterly jet positioned southward and the presence of less African easterly waves activity (e.g., [23]). Another reason may be related to the fact that the warming affects the stability of the atmosphere which in turn drives a dry Sahel [39].

In summary, while ECHAM5 shows negative changes of rainfall and evaporation over the Sahel and positive changes over the Guinea Coast, RegCM3 provides opposite 


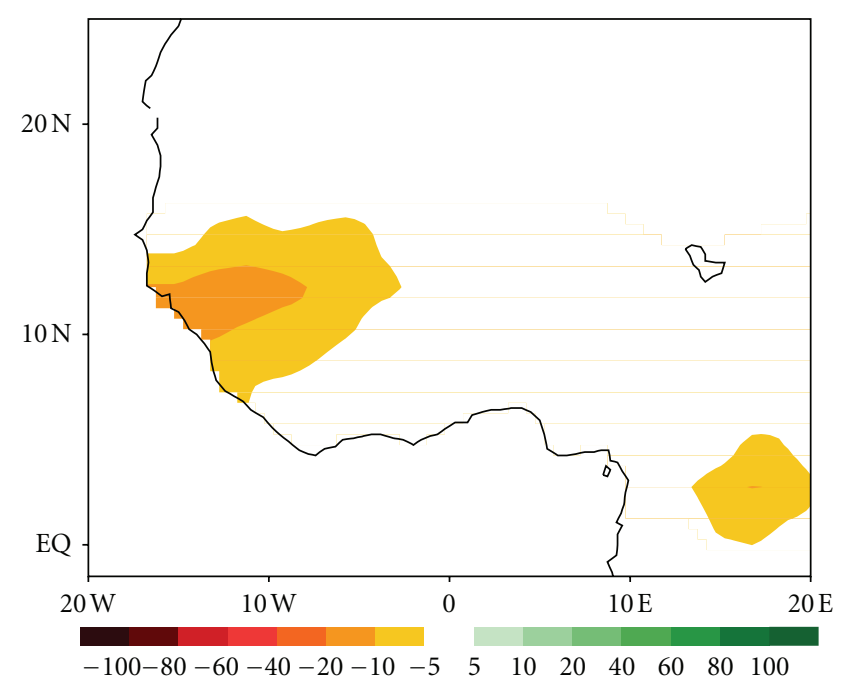

(a) ECHAM5 (2031-2050) minus (1981-2000)

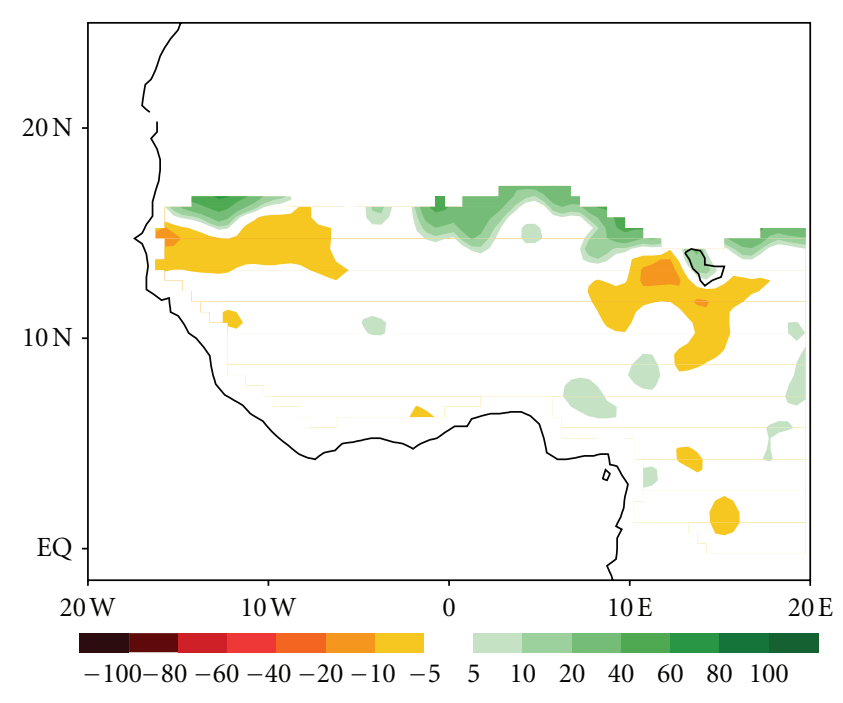

(c) RegCM3 (2031-2050) minus (1981-2000)

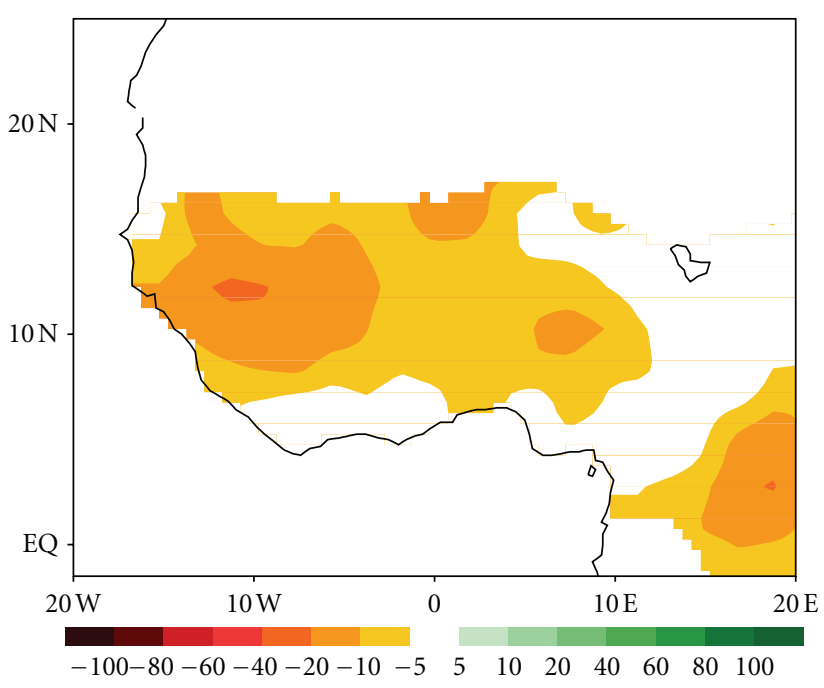

(b) ECHAM5 (2081-2100) minus (1981-2000)

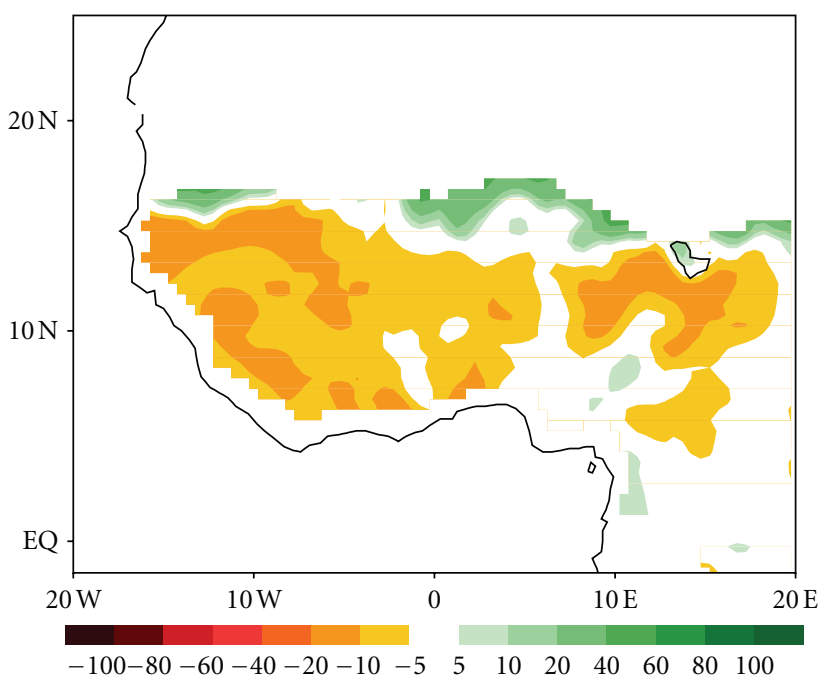

(d) RegCM3 (2081-2100) minus (1981-2000)

FIgURE 4: The same as Figure 3 but for total soil moisture content.

changes between the low-elevation (negative over Sahel and the flatter Gulf of Guinea) and high-elevation terrains (positive mostly over Cameroun Mountains). In addition, both models project elevated precipitable water over the whole West Africa with the larger increase over the peak of Cameroun complex terrains. It is thus evident that surface orography strengthens the water vapour feedback, intensifies the atmospheric hydrological cycle, and gives rise to contrasting climate change signal over West Africa. The role of the complex terrains in shaping the water cycle change is only noticeable in the regional climate model projections. It may stand from orographic uplifting that tends to amplify rainfall amounts in upland areas. However, before discussing the related dynamics that bring about such different changes in Section 3.4, it is worth investigating how these changes affect the characteristics of daily and extreme rainfall events.
3.2. Changes in the Frequency, Intensity, and Extreme Rainfall Events. Changes in the number of wet days from ECHAM5 and $\mathrm{RegCM} 3$ for the early and the late 21 st century are reported in Figures 6(a)-6(d), respectively. ECHAM5 shows significant reduction of the number of wet days over the Sahel and northern Gulf of Guinea during the 21st century. Concerning RegCM3 during the first future time period, only the south-eastern Sahel and Cameroun Mountains undergo significant increase of wet days. For the late 21st century, the increased number of wet days is confined only around the Cameroun Mountains, while a large decrease is projected allover the rest of West Africa. This pattern of the frequency of wet days change is similar to that of the mean rainfall over the Sahel for ECHAM5 and over the whole West Africa for RegCM3. We thus examine the implications of such changes in the intensity of rainfall events. 


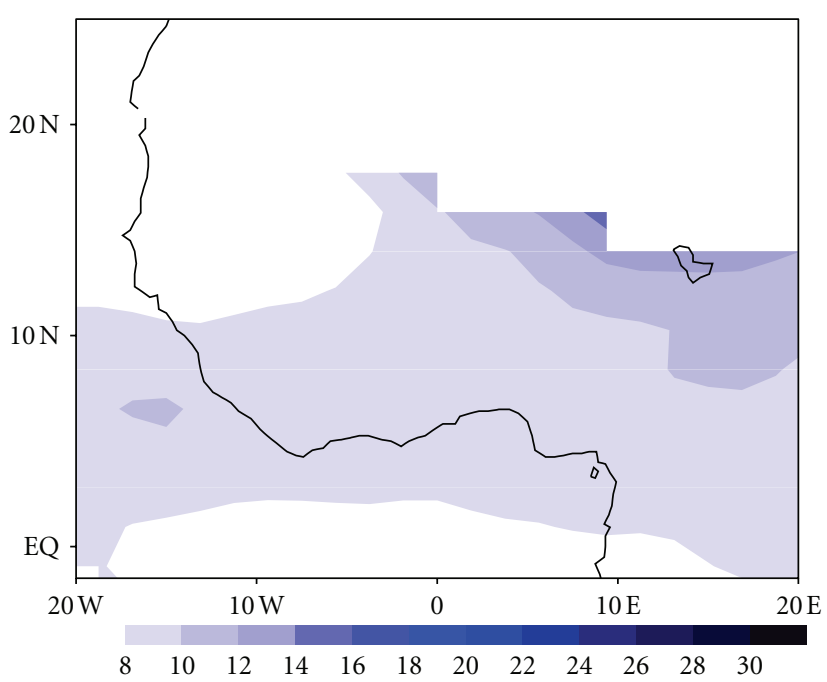

(a) ECHAM5 (2031-2050) minus (1981-2000)

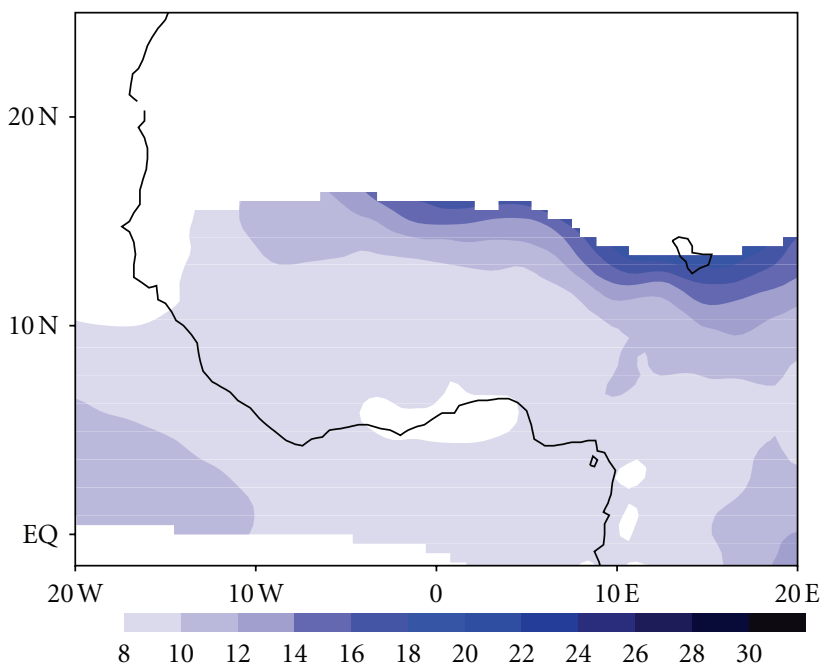

(c) RegCM3 (2031-2050) minus (1981-2000)

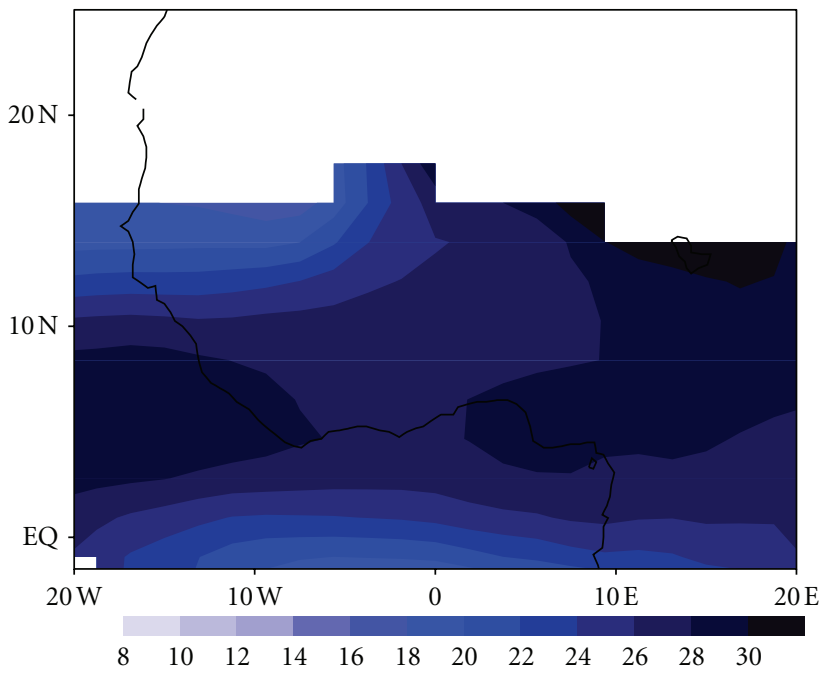

(b) ECHAM5 (2081-2100) minus (1981-2000)

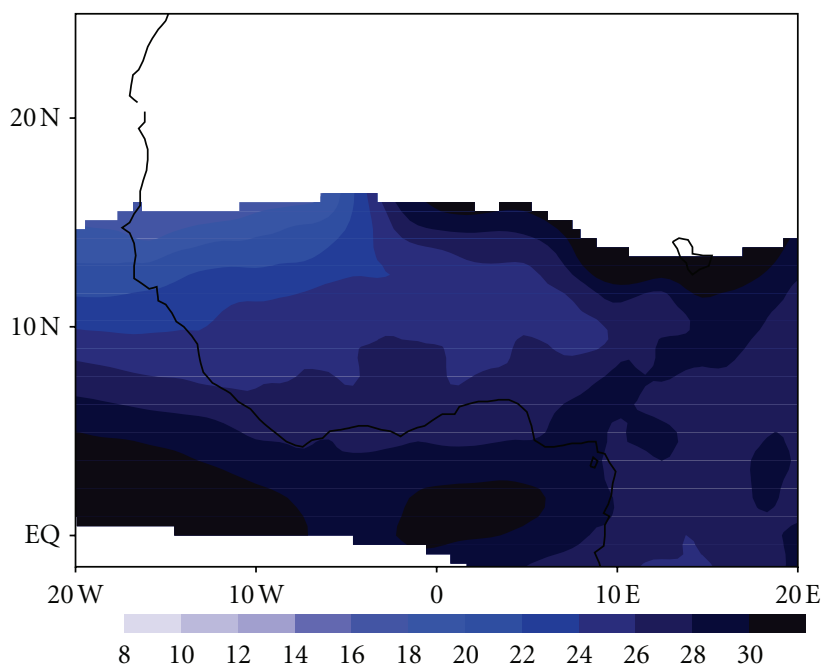

(d) RegCM3 (2081-2100) minus (1981-2000)

Figure 5: The same as Figure 4 but for precipitable water.

In ECHAM5, significant increase of rainfall intensity is projected over the Gulf of Guinea, the eastern Sahel, and the Cameroun mountainous regions during the first future time period and a general increase over the entire West Africa during the late 21 st century (Figures $7(\mathrm{a})$ and $7(\mathrm{~b})$ ). This indicates that the future dryness in the global climate model over the Sahel originates from a reduction of the number of wet days, while the wetness over the Gulf of Guinea is due to increased intensity of rainfall events. RegCM3 projections provide mixed changes during both periods with persistent amplified intensity shown at the peak of Guinea Highlands and Cameroun Mountains, and northern Gulf of Guinea (Figures $7(\mathrm{c})$ and $7(\mathrm{~d})$ ). This pattern suggests that the wetter conditions over the high-elevation terrains arise from the occurrence of more rainy days and a subsequent increase of total rainfall intensity. The combined changes in the frequency and intensity of rainfall events should have strong impacts on the extremes.
The change in the 95th percentile of daily rainfall for ECHAM5 and RegCM3 during both time periods is displayed in Figures $8(\mathrm{a})-8(\mathrm{~d})$, while the corresponding change in the highest one-day precipitation is presented in Figures 9(a)-9(d). In ECHAM5 and RegCM3, the 95th percentile and the highest one-day precipitation changes show similar pattern and follow mostly the corresponding total rainfall intensity expect over the northernmost part of the Sahel which depicts a large decrease of both indices. This indicates that the increase of total rainfall intensity in ECHAM5 over the Gulf of Guinea and in RegCM3 over the complex terrains is due not only to a larger number of wet days but also to the occurrence of more extreme rainfall events. These events have also caused the wetter conditions found in ECHAM5 (RegCM3) projections over the regions encompassing the southern Sahel and lying along the northern Gulf of Guinea (central Gulf of Guinea) where the frequency of rainy days was decreased. 


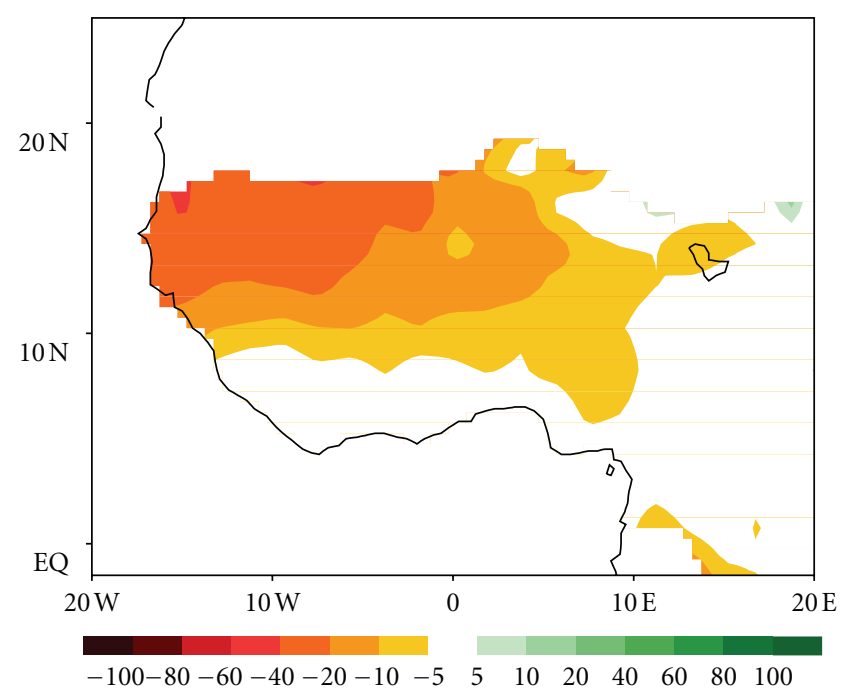

(a) ECHAM5 (2031-2050) minus (1981-2000)

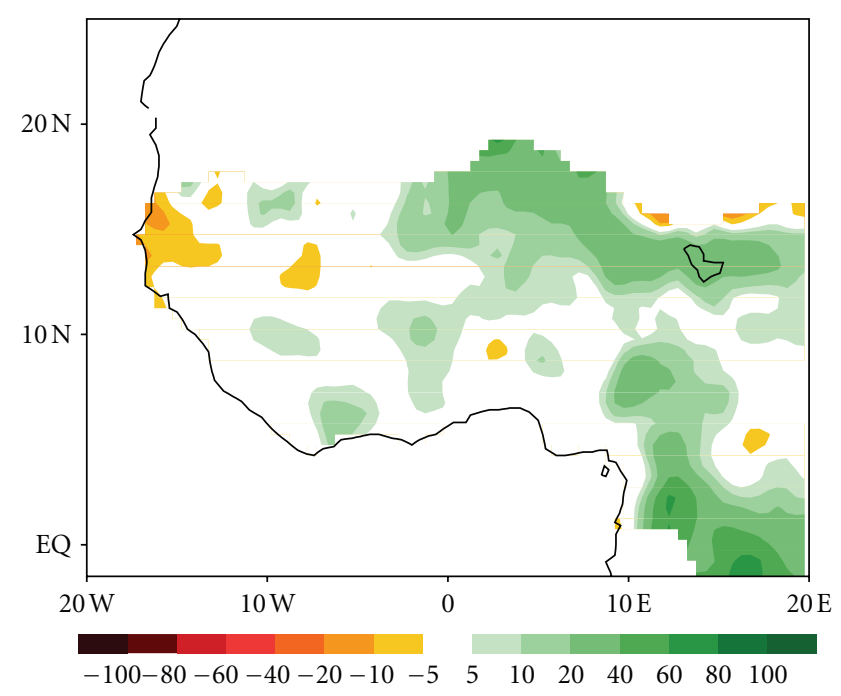

(c) RegCM3 (2031-2050) minus (1981-2000)

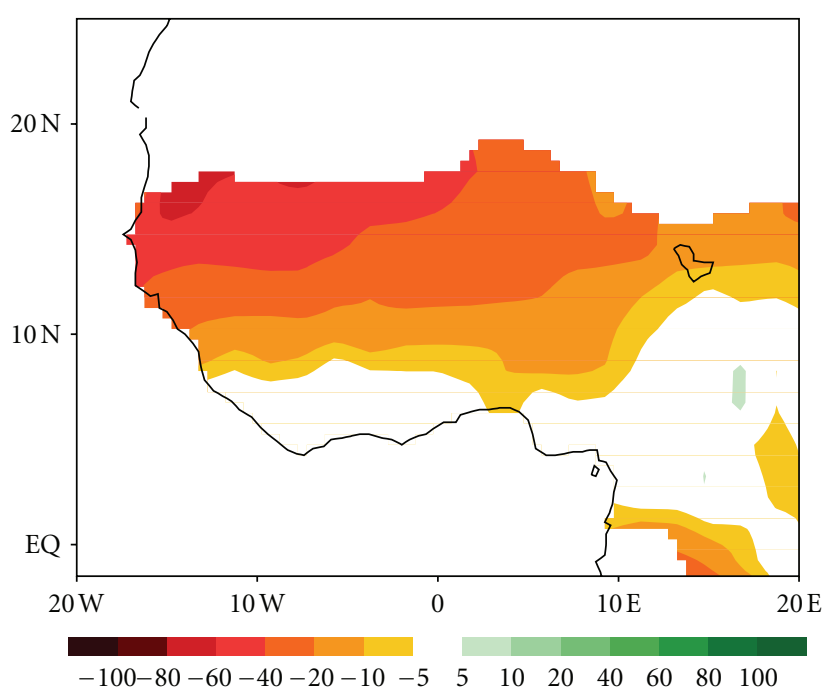

(b) ECHAM5 (2081-2100) minus (1981-2000)

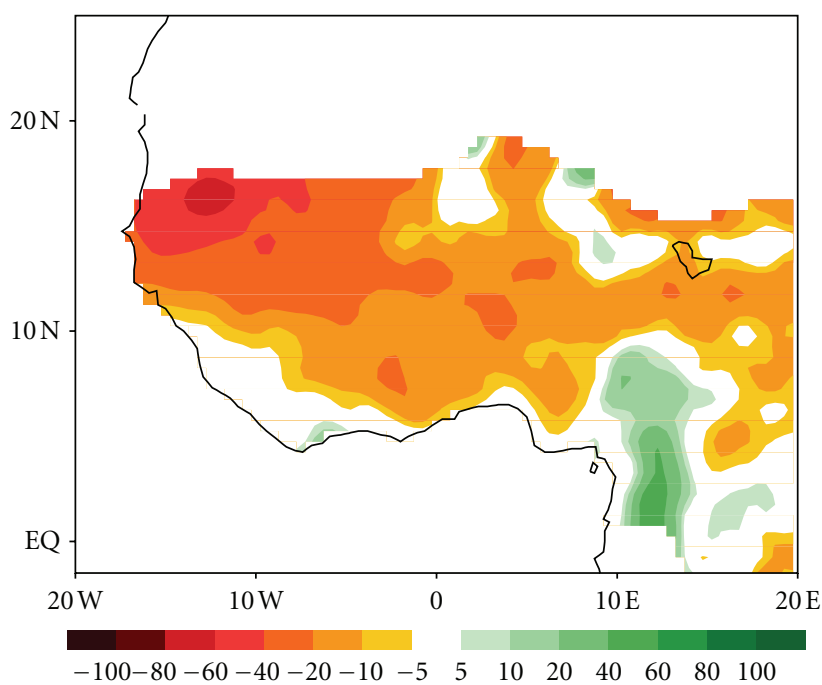

(d) RegCM3 (2081-2100) minus (1981-2000)

Figure 6: The same as Figure 5 but for the frequency of wet days.

It is thus evident that the change in the properties of rainfall events from the regional climate model and the driving global climate model exhibits different characteristics and patterns of the change in frequency, intensity, and extreme indices. In fact, while ECHAM5 shows mostly dipole patterns, the high-resolution RegCM3 differentiates between the low- (negative changes) and high-elevation terrains (positive changes). To further emphasize this fact, we present below the probability density function of daily rainfall over some selected subregions composed by lowelevation terrains (Sahel and central Gulf of Guinea) and uplands (Guinea Highlands and Cameroun Mountains).

3.3. Changes in the Density of Daily Rainfall Events. The probability density functions (PDFs) of daily rainfall events for both ECHAM5 and RegCM3 over the Sahel, Guinea Highlands, low-elevation terrains of Gulf of Guinea, and Cameroun Mountains for the present day, the early, and the late 21 st century periods are shown in Figures 10(a)-10(d). In general, in ECHAM5 simulations, the rainfall density increases with increasing GHG concentration over all the subregions. RegCM3 does not exhibit substantial differences between the present-day and the future daily rainfall density over the Sahel and the low-elevation terrain of the Gulf of Guinea. However, over the complex terrains of Guinea Highlands and Cameroun Mountains, it is noticeable that the regional climate model projects more intense rainfall events. Therefore, similarly to the frequency, intensity, and extremes, the density of rainfall events corroborates the contrasting climate change signal found over the highelevation terrains with respect to the low-elevation areas. 


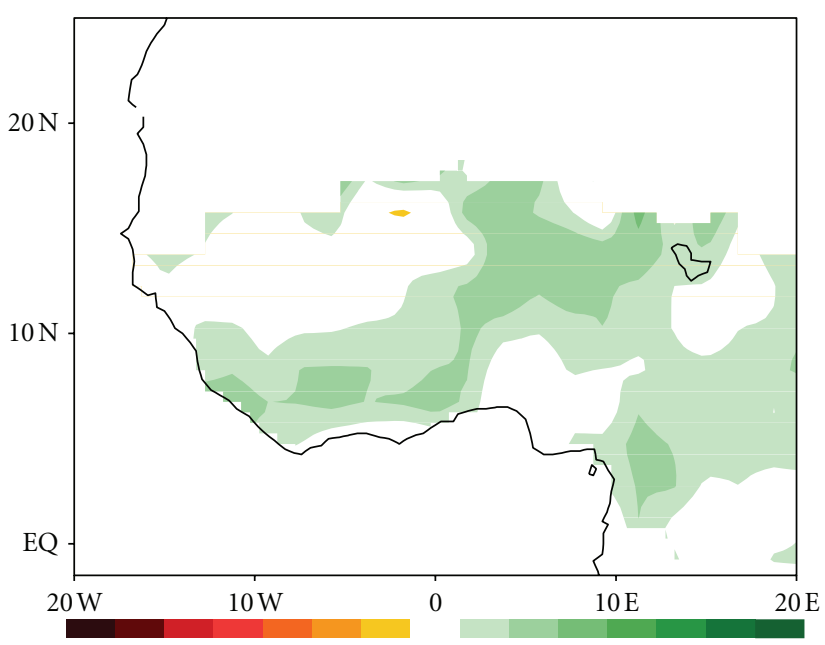

$-100-80-60-40-20-10-5 \quad 5 \quad 10 \quad 20 \quad 40 \quad 60 \quad 80 \quad 100$

(a) ECHAM5 (2031-2050) minus (1981-2000)

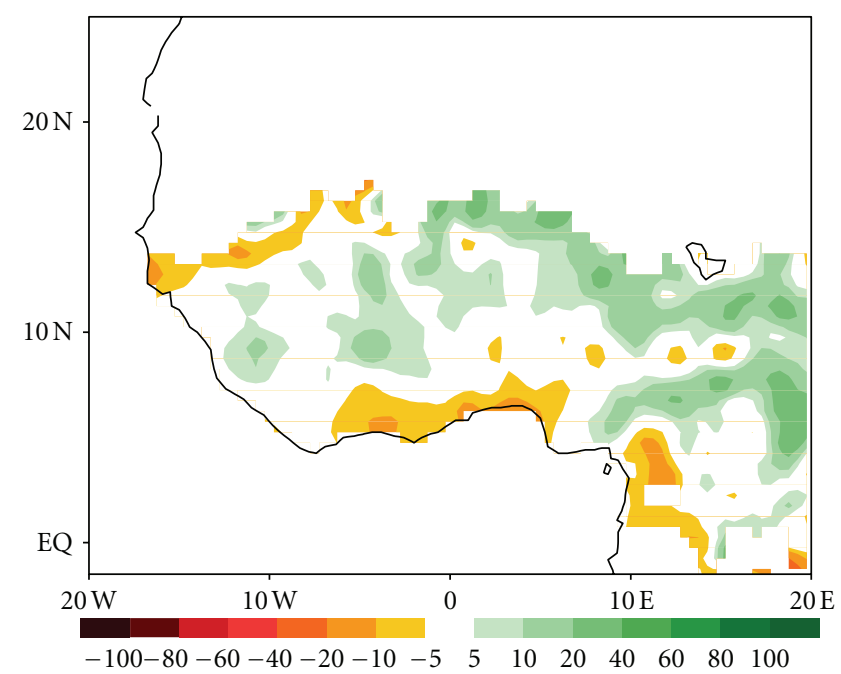

(c) RegCM3 (2031-2050) minus (1981-2000)

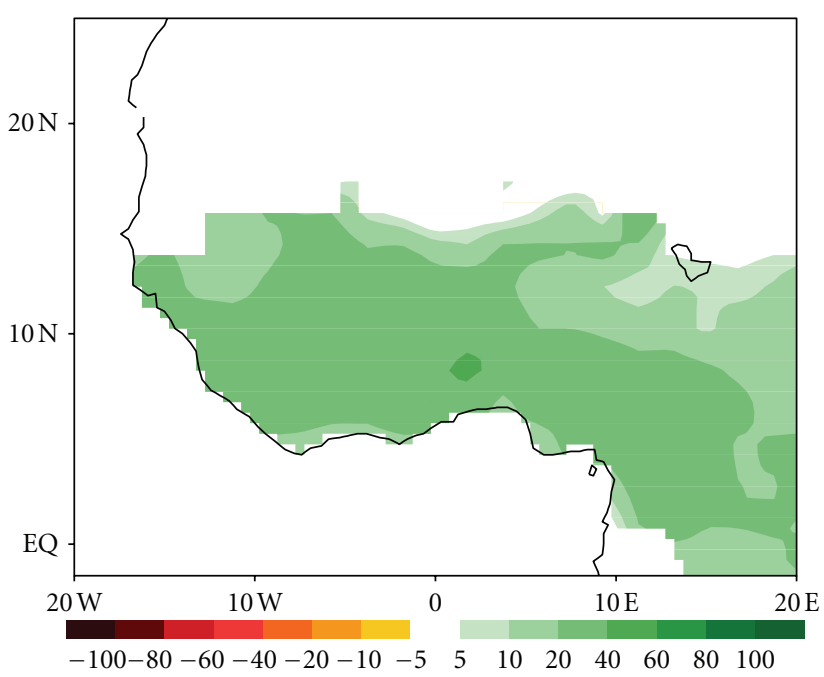

(b) ECHAM5 (2081-2100) minus (1981-2000)

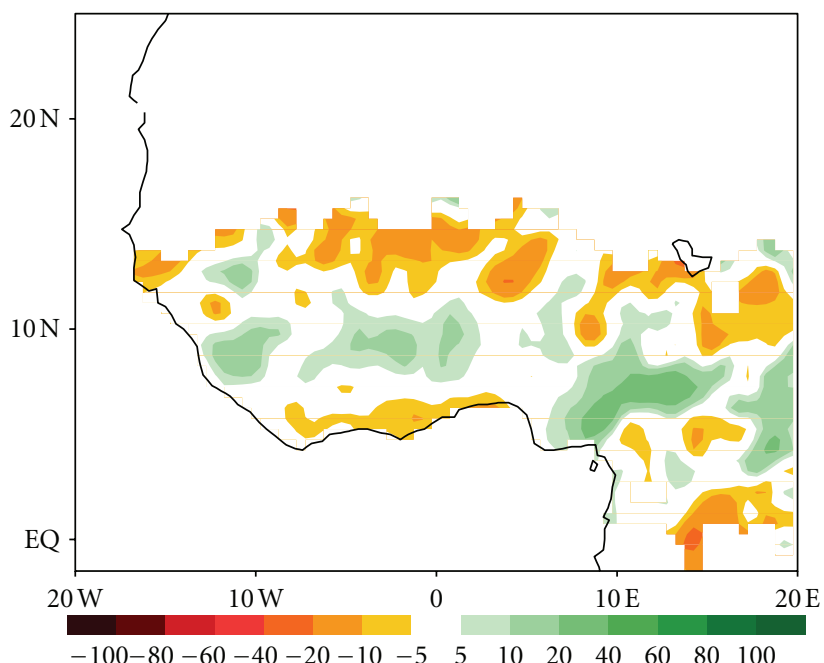

(d) RegCM3 (2081-2100) minus (1981-2000)

Figure 7: Same as Figure 6 but for the intensity of wet days.

This reveals a regulation of the changes in the daily and extreme rainfall events by the topographical features better resolved in RegCM3. We thus investigate the way the Gulf of Guinea orography alters the response of uplands to the West African climate change.

3.4. Changes in Vertical Motion and Low-Level Moisture Convergence. Figures 11(a) and 11(d) show the longitudeheight cross-section of the specific humidity and the overlapping Lagrangian tendency of air pressure (omega) over the Gulf of Guinea (averaged between 4 and $10^{\circ} \mathrm{N}$ ) during the present day for ECHAM5 and RegCM3, respectively. In both models, vertical motion occurs along the entire zonal band with stronger core above the mountainous regions of Guinea Highlands and Cameroun. The humidity is larger in the lower levels but decreases gradually with altitudes and reaches values that are less than $1 \mathrm{~g} / \mathrm{kg}$ above
$450 \mathrm{hPa}$. The atmospheric moisture mostly increases with GHG concentration; however, the high percentage at the upper troposphere during the future is certainly amplified by the presence of very low values of specific humidity during the present day there (Figures 11(b), 11(c), 11(e), and 11(f)). In ECHAM5, the changes in omega indicates elevated vertical motion at all levels between $10^{\circ} \mathrm{W}$ and $20^{\circ} \mathrm{W}$ (i.e., the western Gulf of Guinea) during both future time periods. At the end of the 21st century, such increasing vertical motions are extended along the entire Gulf of Guinea and at the midlevels. In RegCM3, the deepening of the vertical motion core and the subsequent larger specific humidity at the midlevels are only projected above the mountainous areas of Cameroun. This indicates that while ECHAM5 smoothes it along the entire Gulf of Guinea, the high-resolution regional climate model favours elevated atmospheric instability and moisture only above high-elevation terrains. We should 


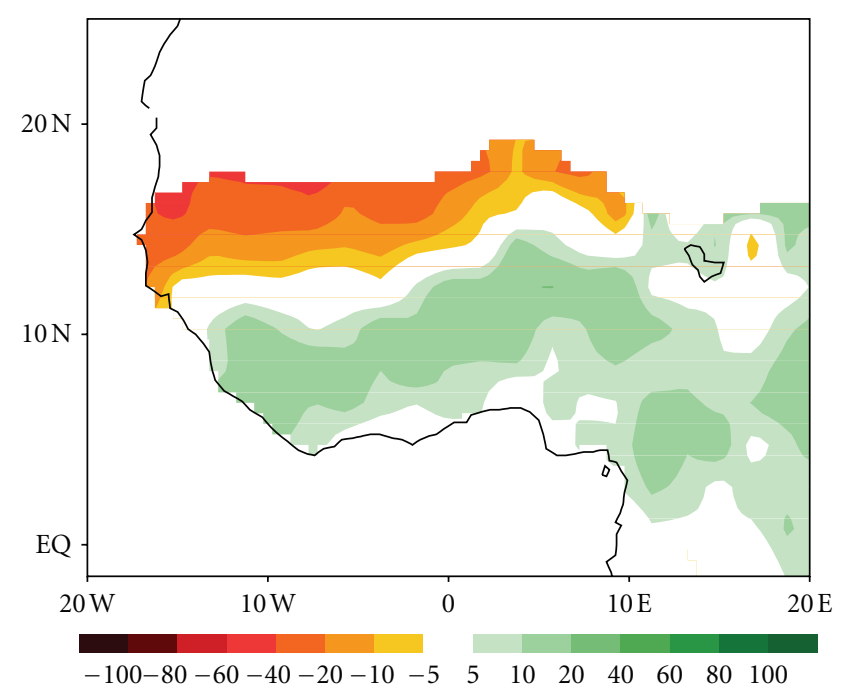

(a) ECHAM5 (2031-2050) minus (1981-2000)

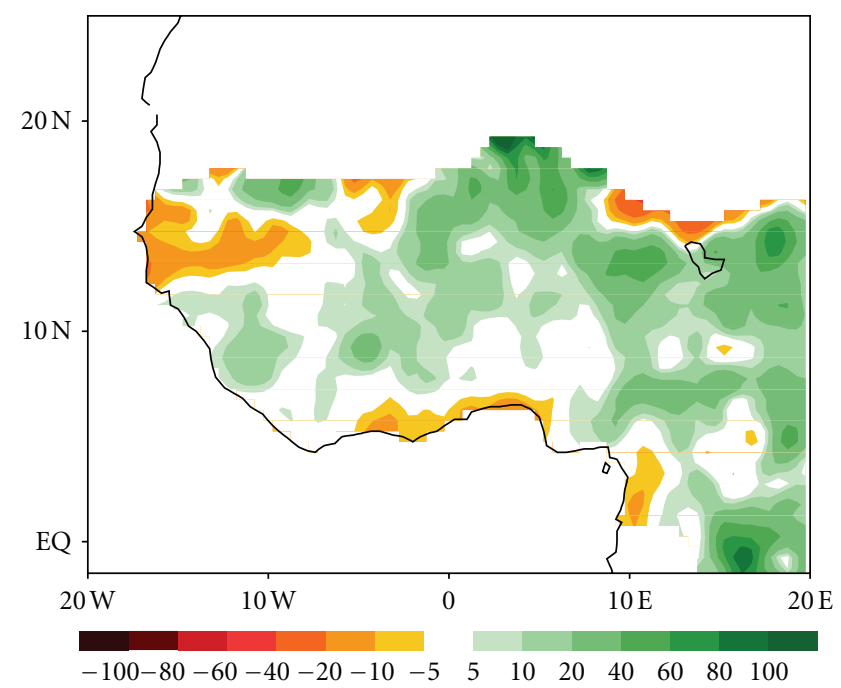

(c) RegCM3 (2031-2050) minus (1981-2000)

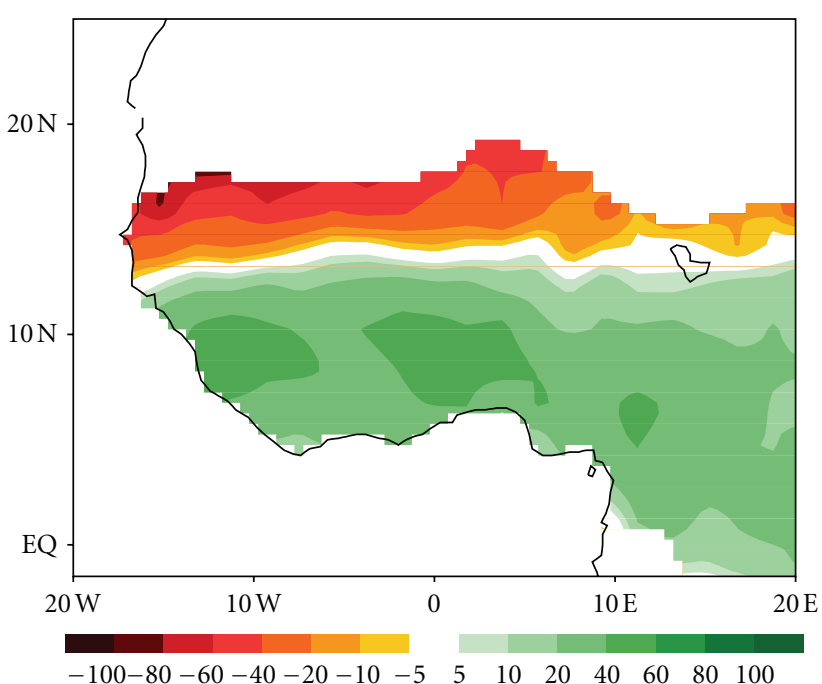

(b) ECHAM5 (2081-2100) minus (1981-2000)

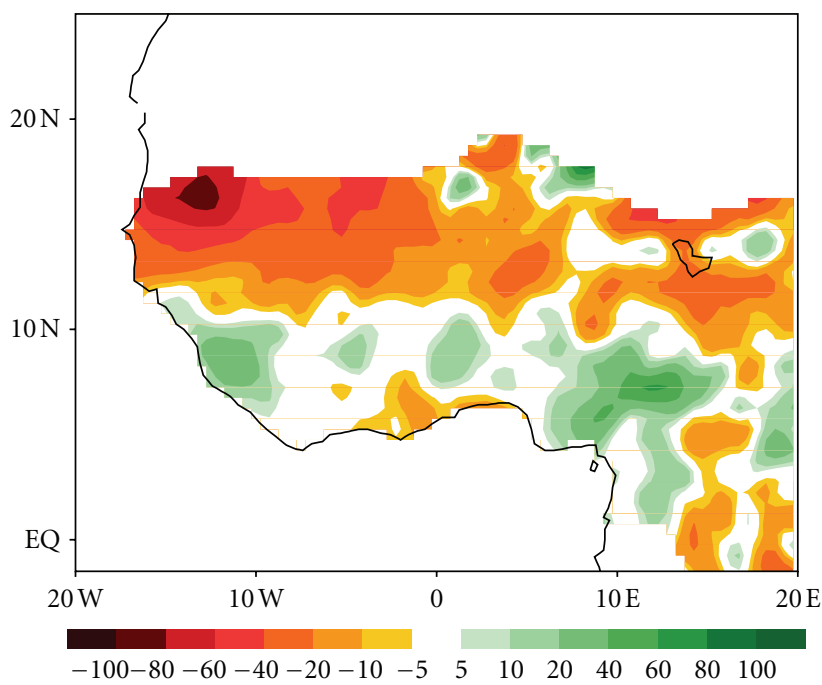

(d) RegCM3 (2081-2100) minus (1981-2000)

Figure 8: The same as Figure 7 but for the 95th percentile.

emphasize that this difference is due to the fact that the topographical features are better resolved by the regional climate model. This is consistent with the disparities found in the pattern of rainfall changes shown by the driving global model with respect to the nested model. In fact, forced mechanical lifting of the air mass due to mountains leads to cooling of the air column, resulting in condensation and precipitation. More mechanisms in the association between orography and precipitation have been reviewed by Roe [40]. All of them are processes that affect not only the initiation but also the intensification of precipitation. Therefore, the changes in omega and specific humidity appear to explain the alteration of the West African climate change by highelevation terrains. The reasons of such behaviour may be related to the moisture flux convergence.
Given that the maximum increase of vertical motion is mostly centered around $700 \mathrm{hPa}$, we show in Figures $12(\mathrm{a})-12$ (f) the $700 \mathrm{hPa}$ moisture flux convergence for ECHAM5 and RegCM3 during the present day, the early, and the late 21st century, respectively. Both models exhibit a dipole pattern consisting of a continental moisture flux convergence in the Gulf of Guinea and the southern Sahel and divergence in the regions above. In ECHAM5, the convergence (divergence) amplifies with increasing GHG concentration along the entire Gulf of Guinea (the Sahel and the Sahara). However, in RegCM3, although the divergence is increased, the convergence does not show any substantial discrepancies between the different time periods along the Gulf of Guinea except around Cameroun Mountains. Therefore, the strengthening of the vertical motion core in 


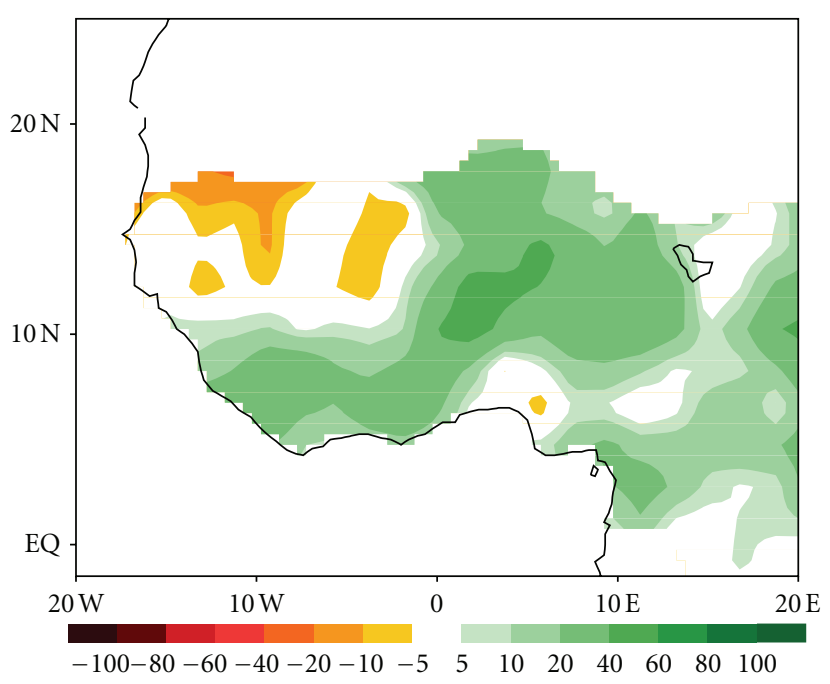

(a) ECHAM5 (2031-2050) minus (1981-2000)

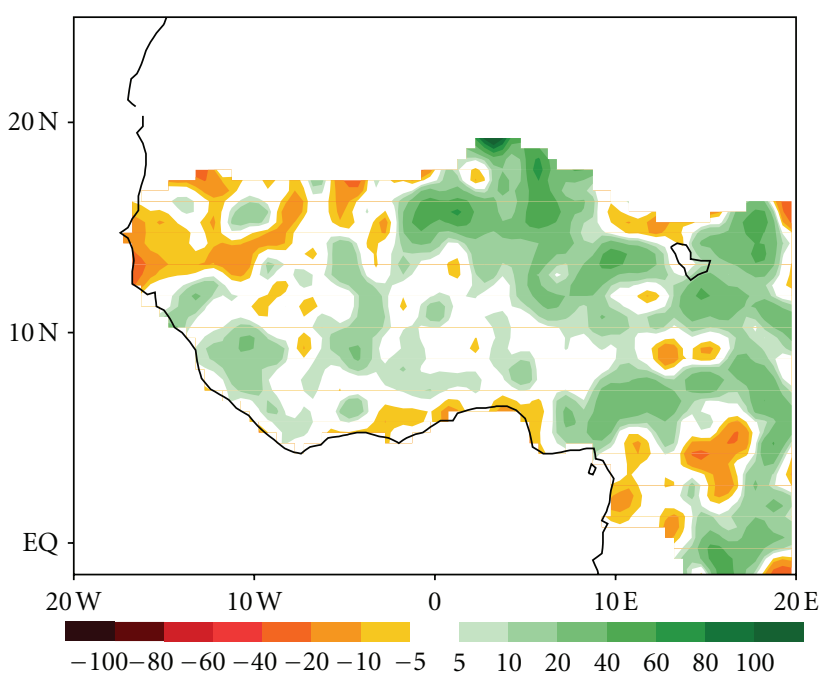

(c) RegCM3 (2031-2050) minus (1981-2000)

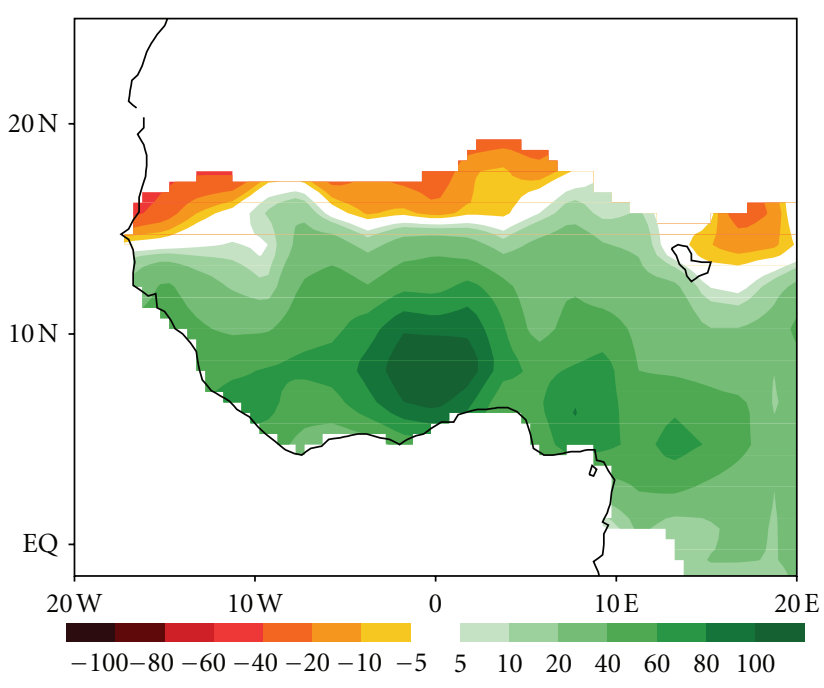

(b) ECHAM5 (2081-2100) minus (1981-2000)

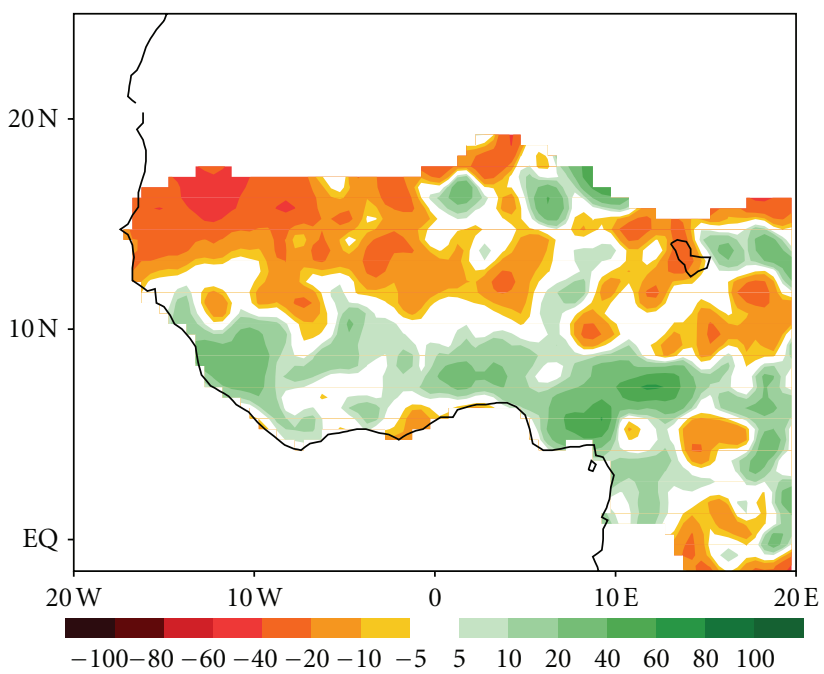

(d) RegCM3 (2081-2100) minus (1981-2000)

Figure 9: The same as Figure 8 but for the highest one-day precipitation.

RegCM3 (ECHAM5) during the future time periods is due to intensification of the low-level moisture flux convergence around mountainous areas of Cameroun (entire Gulf of Guinea).

\section{Summary and Conclusion}

In this paper, projections from a regional climate model and the driving global climate model for two future time periods are assessed and intercompared over West Africa. In particular, we investigate how the high-elevation terrains alter the response of the atmospheric water cycle and extreme rainfall events to the increasing GHG concentration.

In RegCM3, the low-elevation regions, specifically the Sahel and the central Gulf of Guinea, undergo a drying under global warming conditions, while complex terrains such as Cameroun Mountains and peak of the Guinea
Highlands exhibit wetter conditions during both periods compared to the present day. This contrast between highand low-elevation terrains is not shown in the global model projections. In fact, that latter projects wetter climates along all the Guinea Coast and drier climates in the Sahel. This smoothing of the climate change signal is believed to be caused by the coarse resolution of the GCM which does not properly resolve the surface heterogeneity such as complex terrains.

Similar changes are found in the other components of the hydrological cycle. In fact, the wetter conditions projected in the uplands (Guinea Coast) by RegCM3 (ECHAM5) are accompanied by an increase of evaporation and precipitable water indicating a strengthening of the water vapour feedback and an intensification of the atmospheric hydrological cycle. No significant changes are found for the total soil moisture content over these regions suggesting that 


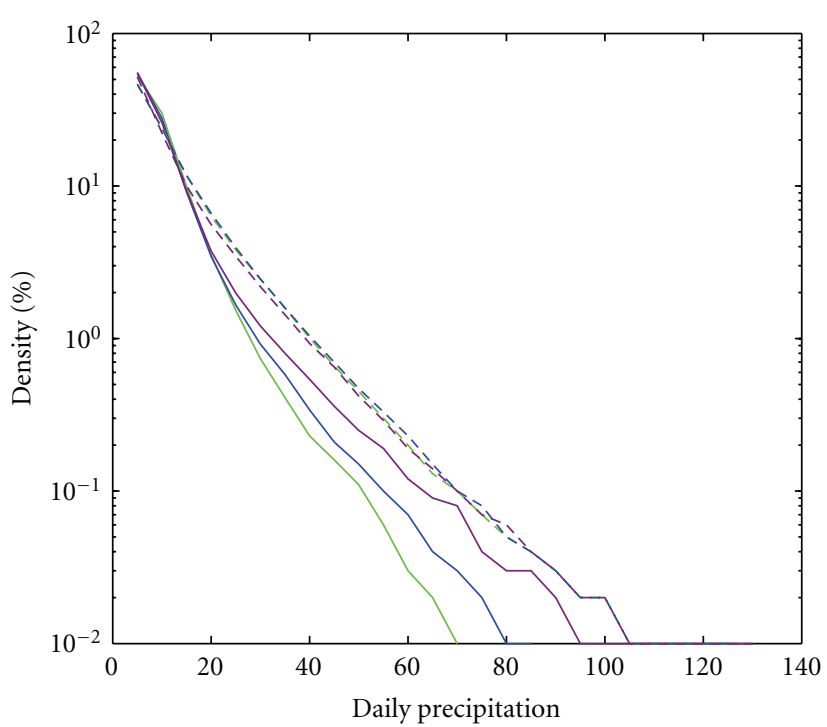

(a) Sahel

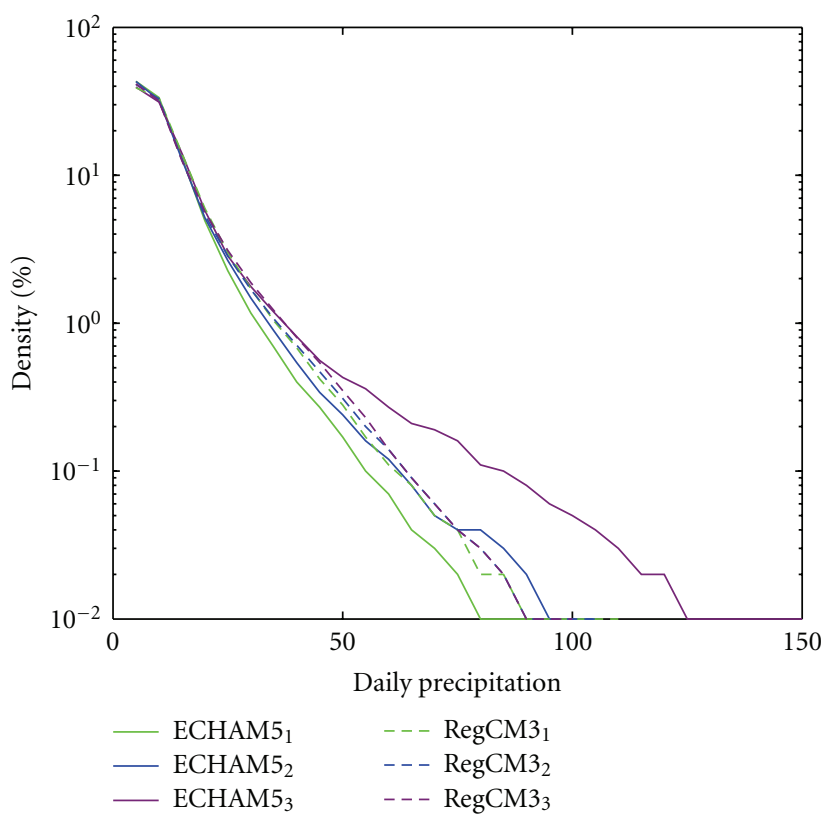

(c) Guinea Coast

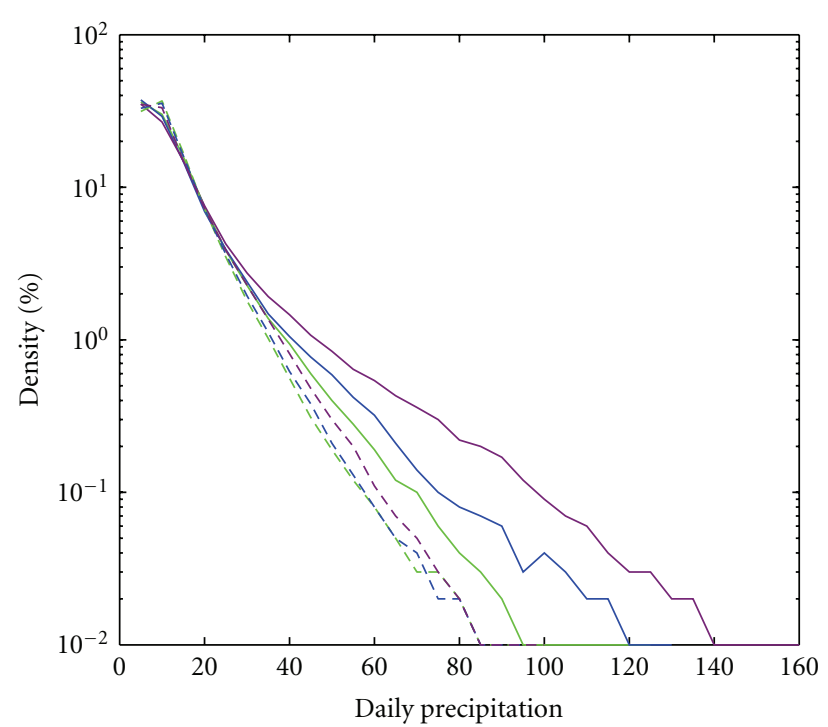

(b) Guinea Highlands

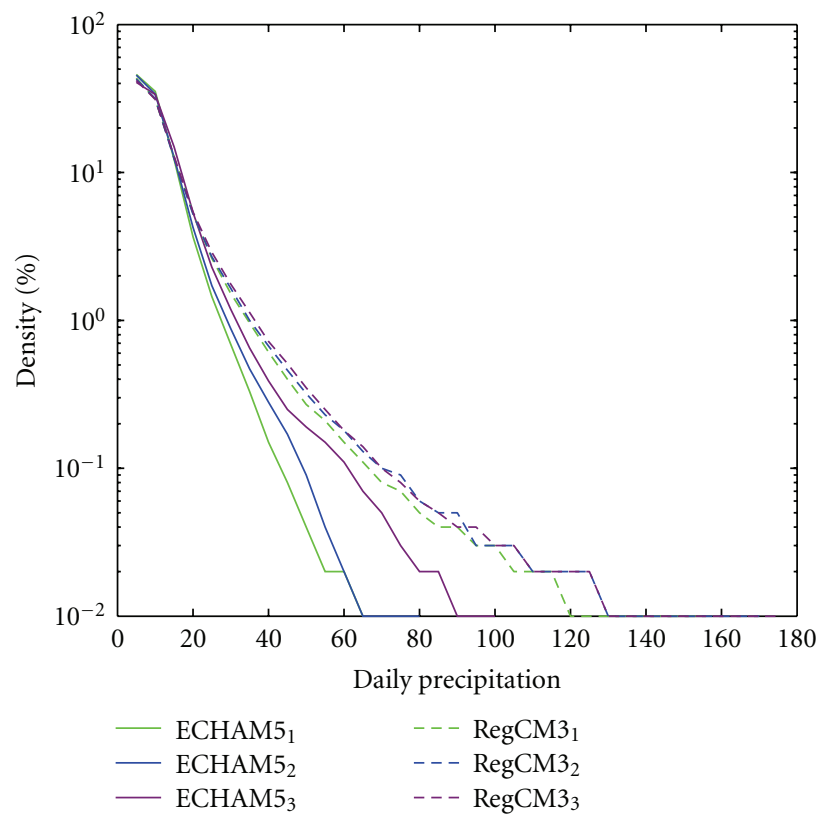

(d) Cameroun Mountains

Figure 10: Probability density functions of daily rainfall over (a) the Sahel, (b) the Guinea Highlands, (c) the low elevation terrains of Gulf of Guinea, and (d) the Cameroun Mountains from ECHAM5 (solid lines) and RegCM3 (dashed lines) during the summer season (June-August) of the present day (green lines), the early (blue lines), and the late (violet lines) 21st century.

precipitation change drives the evaporation change. Changes in the frequency, the total intensity, the 95th percentile, and the highest one-day precipitation follow mostly the change in mean rainfall climatology. Therefore, the amplification of the hydrological cycle occurs mostly as a consequence of more frequent, dense, and intense rainy days leading to overall larger total amount. These characteristics of the rainfall events are also shown by the ECHAM5 but along the entire Guinea Coast, while RegCM3 confines them only over the high-elevation terrains. It is thus evident that surface orography regulates the changes of the daily and extreme rainfall events.

To emphasize the dynamics that bring about such changes, we examine the differences between the future and the present-day periods in the Lagrangian tendency of air pressure, characterizing the vertical motion, and in the low-level moisture flux convergence over the Gulf of Guinea. The global climate model projects a strengthening of the vertical motion over the western Guinea Coast during the first time period and along the entire Gulf of 


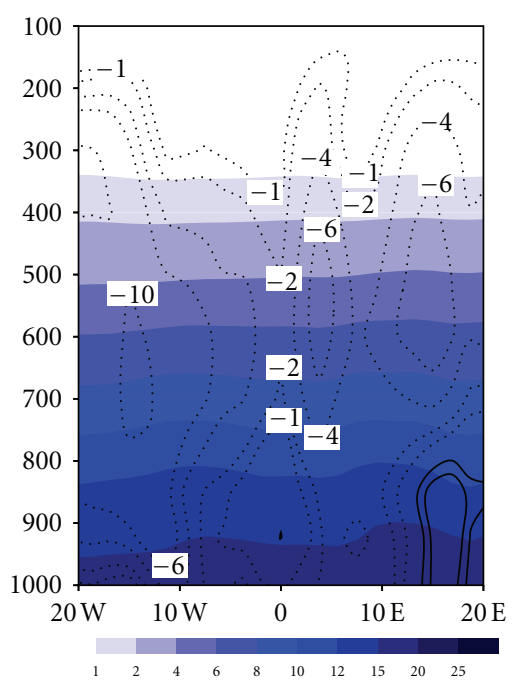

(a) ECHAM5 omega and Q 1981-2000

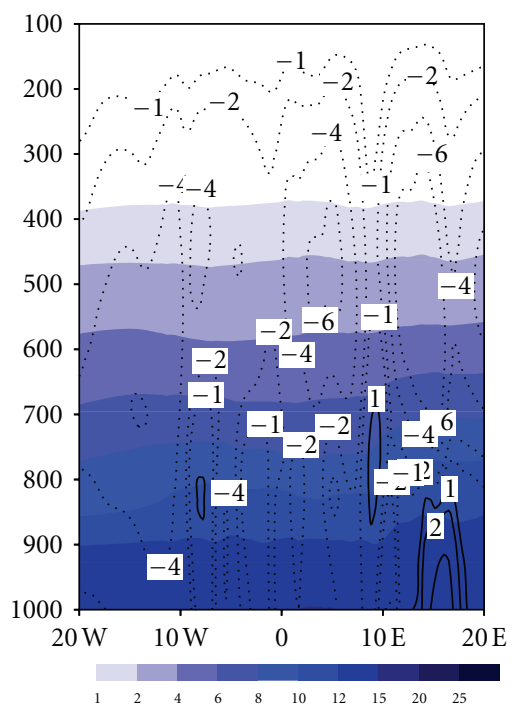

(d) RegCM3 omega and Q 1981-2000

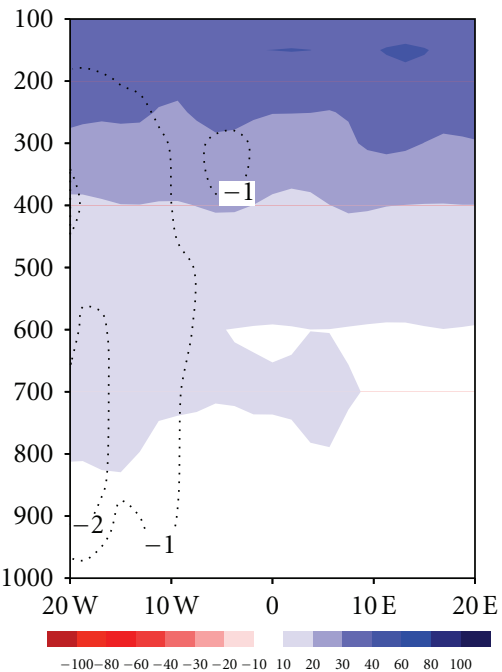

(b) 2031-2050 minus 1981-2000

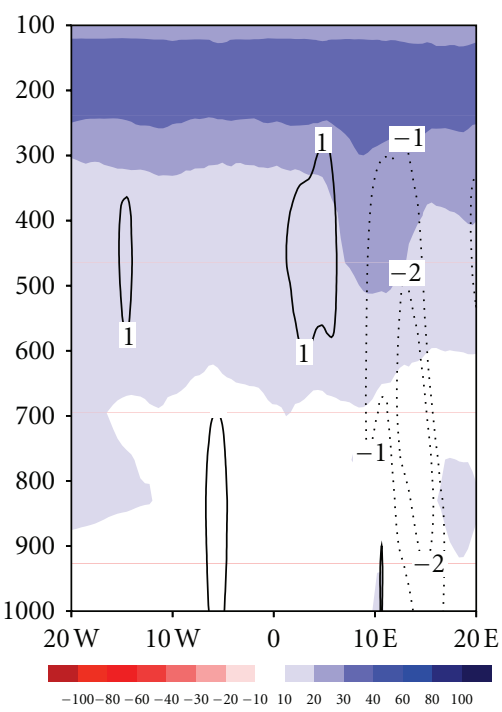

(e) 2031-2050 minus 1981-2000

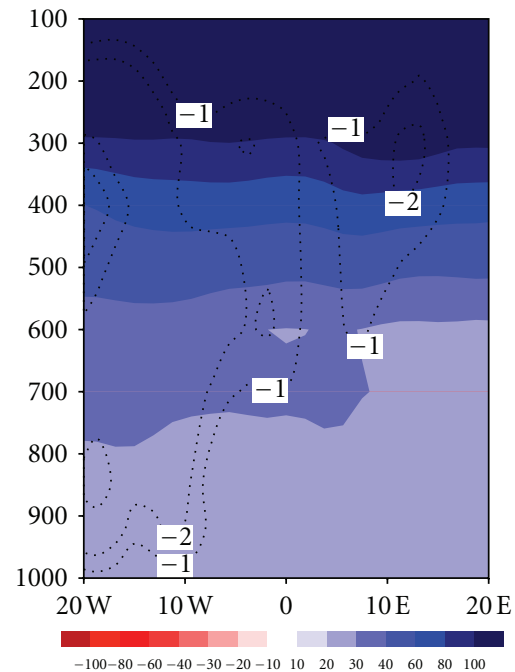

(c) 2081-2100 minus 1981-2000

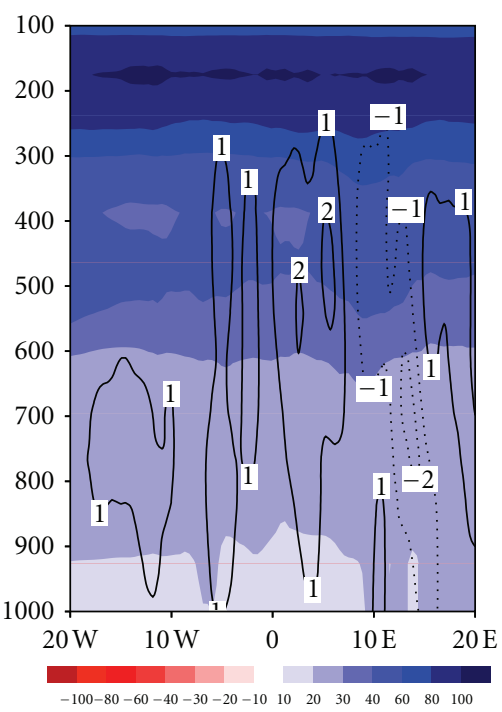

(f) 2081-2100 minus 1981-2000

Figure 11: Mean summer (June-August) longitude-height cross-section of specific humidity $(\mathrm{g} / \mathrm{kg})$ and overlapping omega $\left(10^{-3} \mathrm{~Pa} / \mathrm{s}\right)$ from ECHAM5 (upper) and RegCM3 (lower) during the present day (left), the difference between early 21st century and the present day (middle), and the difference between late 21st century and the present day (right). Negative contours represent regions of ascent, and positive contours are regions of descent.

Guinea during the late 21st century. However, in RegCM3 projections, the vertical motion core deepens only above the mountainous region of Cameroun suggesting more atmospheric instability which favours increased rainfall. The deepening of this ascent results from a intensification of the low-level moisture flux convergence during the two future time periods around the orographic regions of Cameroun. Therefore, in ECHAM5 (RegCM3) projections along the Gulf of Guinea (Cameroun Mountains), increase of the moisture flux convergence induces elevated vertical motion favouring more atmospheric instability which amplifies the hydrological cycle during the future time periods. We should note that this fine-scale topography shaping the response of large-scale dynamics and the subsequent rainfall and extremes to the increasing GHG concentration is only evident using the resolution regional climate model.

This highlights the need to use regional climate models to dynamically downscale global climate model output in order to provide future regional and/or local climate change information required for suitable impact studies over West Africa. However, this needs to be tested using ensembles of regional and global climate models before drawing any firm conclusion. The coordinated regional climate downscaling experiment framework (CORDEX, [41]) will then offer this opportunity. 


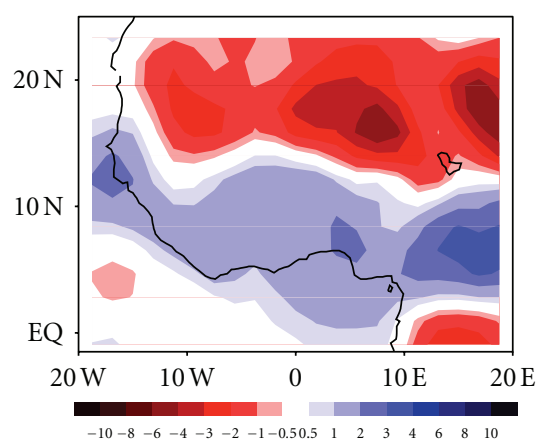

(a) ECHAM5 $700 \mathrm{hPa}$ moisture conv. 19812000

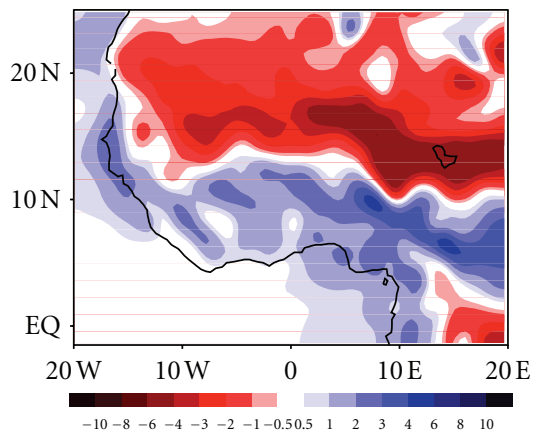

(d) RegCM3 $700 \mathrm{hPa}$ moisture conv. 19812000

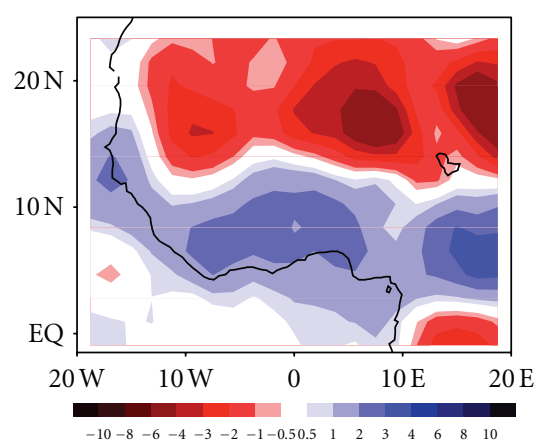

(b) ECHAM5 $700 \mathrm{hPa}$ moisture conv. 20312050

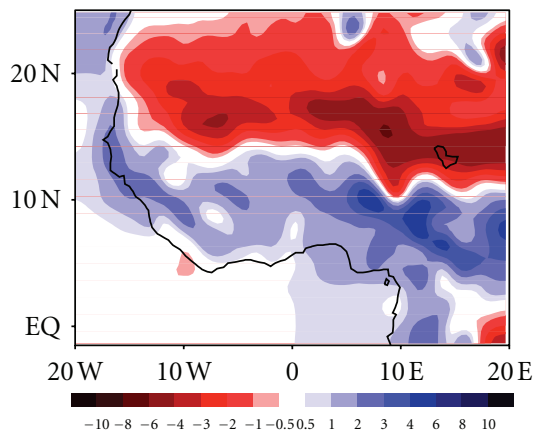

(e) RegCM3 700 hPa moisture conv. 2031-2050

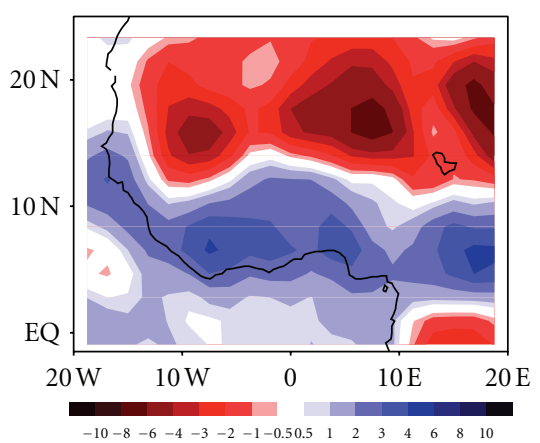

(c) ECHAM5 $700 \mathrm{hPa}$ moisture conv. 20812100

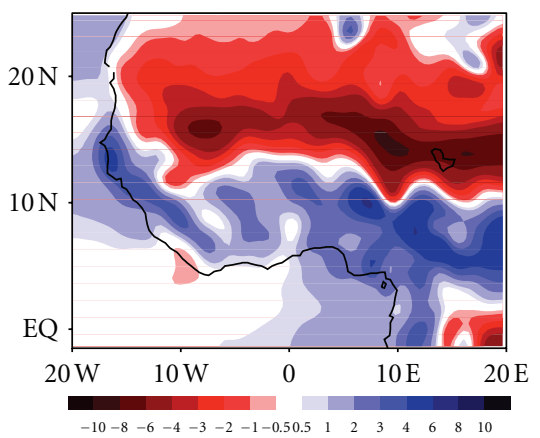

(f) RegCM3 $700 \mathrm{hPa}$ moisture conv. 2081-2100

Figure 12: Mean summer (June-August) low-level moisture flux convergence from ECHAM5 (upper) and RegCM3 (lower) during the present day (left), the early (middle), and the late (right) 21 st century. Units are expressed as $\mathrm{s}^{-1}$. Positive shades represent convergence, while negative shades define divergence.

\section{References}

[1] A. F. Kamga, G. S. Jenkins, A. T. Gaye, A. Garba, A. Sarr, and A. Adedoyin, "Evaluating the National Center for Atmospheric Research climate system model over West Africa: presentday and the 21st century A1 scenario," Journal of Geophysical Research D, vol. 110, Article ID D03106, 18 pages, 2005.

[2] M. Hulme, R. Doherty, T. Ngara, M. New, and D. Lister, "African climate change: 1900-2100," Climate Research, vol. 17, no. 2, pp. 145-168, 2001.

[3] A. Giannini, M. Biasutti, I. M. Held, and A. H. Sobel, "A global perspective on African climate," Climatic Change, vol. 90, no. 4, pp. 359-383, 2008.

[4] M. Biasutti and A. Giannini, "Robust Sahel drying in response to late 20th century forcings," Geophysical Research Letters, vol. 33, Article ID L11706, 4 pages, 2006.

[5] M. Hoerling, J. Hurrell, J. Eischeid, and A. Phillips, "Detection and attribution of twentieth-century northern and southern African rainfall change," Journal of Climate, vol. 19, no. 16, pp. 3989-4008, 2006.

[6] F. Giorgi and L. O. Mearns, "Introduction to special section: regional climate modelling revisited," Journal of Geophysical Research, vol. 104, pp. 6335-6352, 1999.

[7] F. Giorgi, C. S. Brodeur, and G. T. Bates, "Regional climate change scenarios over the United States produced with a nested regional climate model," Journal of Climate, vol. 7, pp. 375-399, 1994.

[8] L. O. Mearns, F. Giorgi, L. McDaniel, and C. Shields, "Analysis of daily variability of precipitation in a nested regional climate model: comparison with observations and doubled $\mathrm{CO}_{2}$ results," Global and Planetary Change, vol. 10, no. 1-4, pp. 55-78, 1995.

[9] O. B. Christensen, J. H. Christensen, B. Machenhauer, and M. Botzet, "Very high-resolution regional climate simulations over Scandinavia: present climate," Journal of Climate, vol. 11, pp. 3204-3229, 1998.

[10] J. S. Pal, F. Giorgi, X. Bi et al., "Consistency of recent European summer precipitation trends and extremes with future regional climate projections," Geophysical Research Letters, vol. 31, Article ID L13202, 4 pages, 2004.

[11] F. Giorgi, X. Bi, and J. Pal, "Mean, interannual variability and trends in a regional climate change experiment over Europe. II: climate change scenarios (2071-2100)," Climate Dynamics, vol. 23, no. 7-8, pp. 839-858, 2004.

[12] X. Gao, J. S. Pal, and F. Giorgi, "Projected changes in mean and extreme precipitation over the Mediterranean region from a high resolution double nested RCM simulation," Geophysical Research Letters, vol. 33, Article ID L03706, 4 pages, 2006.

[13] L. Mariotti, E. Coppola, M. B. Sylla, F. Giorgi, and C. Piani, "Regional climate model simulation of projected 21st century climate change over an all-Africa domain: comparison analysis of nested and driving model results," Journal of Geophysical Research, vol. 116, Article ID D15111, 12 pages, 2011.

[14] H. Paeth, N. M. Hall, and M. A. Gaertner, "Progress in regional downscaling of west African precipitation," Atmospheric Science Letters, vol. 12, pp. 75-82, 2011.

[15] G. S. Jenkins, A. T. Gaye, and B. Sylla, "Late 20th century attribution of drying trends in the Sahel from the Regional 
Climate Model (RegCM3)," Geophysical Research Letters, vol. 32, Article ID L22705, 4 pages, 2005.

[16] R. Ramel, H. Gallé, and C. Messager, "On the northward shift of the West African monsoon," Climate Dynamics, vol. 26, no. 4, pp. 429-440, 2006.

[17] H. Paeth, K. Born, R. Girmes, R. Podzun, and D. Jacob, "Regional climate change in tropical and Northern Africa due to greenhouse forcing and land use changes," Journal of Climate, vol. 22, no. 1, pp. 114-132, 2009.

[18] W. Moufouma-Okia and D. P. Rowell, "Impact of soil moisture initialisation and lateral boundary conditions on regional climate model simulations of the West African Monsoon," Climate Dynamics, vol. 35, no. 1, pp. 213-229, 2010.

[19] M. B. Sylla, F. Giorgi, P. M. Ruti, S. Calmanti, and A. Dell'Aquila, "The impact of deep convection on the West African summer monsoon climate: a regional climate model sensitivity study," Quarterly Journal of the Royal Meteorological Society, vol. 137, pp. 1417-1430, 2011.

[20] N. A. K. Browne and M. B. Sylla, "Regional climate model sensitivity to domain size for the simulation of the West African Monsoon rainfall," International Journal of Geophysics. In press.

[21] J. S. Pal, F. Giorgi, X. Bi et al., "The ICTP RegCM3 and RegCNET: regional climate modeling for the developing world," Bulletin of American Meteorological Society, vol. 88, pp. 1395-1409, 2007.

[22] M. B. Sylla, A. T. Gaye, J. S. Pal, G. S. Jenkins, and X. Q. Bi, "High-resolution simulations of West African climate using regional climate model (RegCM3) with different lateral boundary conditions," Theoretical and Applied Climatology, vol. 98, no. 3-4, pp. 293-314, 2009.

[23] M. B. Sylla, A. T. Gaye, G. S. Jenkins, J. S. Pal, and F. Giorgi, "Consistency of projected drought over the Sahel with changes in the monsoon circulation and extremes in a regional climate model projections," Journal of Geophysical Research D, vol. 115, Article ID D16108, 9 pages, 2010.

[24] E. Roeckner, G. Bäuml, L. Bonaventura et al., "The atmospheric general circulation model ECHAM5. Part I: model description," Tech. Rep. 349, Max-Planck-Institut für Meteorologie, Hamburg, Germany, 2003.

[25] J. H. Jungclaus, N. Keenlyside, M. Botzet et al., "Ocean circulation and tropical variability in the coupled model ECHAM5/MPI-OM," Journal of Climate, vol. 19, no. 16, pp. 3952-3972, 2006.

[26] A. F. Kamga and E. Buscarlet, "Simulation du climat de l'Afrique de l'Ouest à l'aide d'un modèle climatique régional," La Meteorologie, vol. 52, pp. 28-37, 2006.

[27] F. Giorgi and E. Coppola, "Does the model regional bias affect the projected regional climate change? An analysis of global model projections, a letter," Climatic Change, vol. 100, no. 3, pp. 787-795, 2010.

[28] N. Nakicenovic et al., IPCC Special Report on Emissions Scenarios, Cambridge University Press, Cambridge, UK, 2000.

[29] F. Giorgi, M. R. Marinucci, and G. T. Bates, "Development of a second-generation regional climate model (RegCM2). Part I: boundary-layer and radiative transfer processes," Monthly Weather Review, vol. 121, no. 10, pp. 2794-2813, 1993.

[30] F. Giorgi, M. R. Marinucci, G. T. Bates, and G. D. Canio, "Development of a second-generation regional climate model (RegCM2). Part II: convective processes and assimilation of lateral boundary conditions," Monthly Weather Review, vol. 121, no. 10, pp. 2814-2832, 1993.

[31] G. A. Grell, J. Dudhia, and D. R. Stauffer, "Description of the fifth generation Penn State/NCAR Mesoscale Model (MM5),"
Technical Note NCAR/TN-398+STR, National Center for Atmospheric Research, Boulder, Colo, USA, 1994.

[32] J. T. Kiehl, J. J. Hack, G. B. Bonan et al., "Description of the NCAR Community Climate Model (CCM3)," Tech. Rep. TN-420+STR, National Center for Atmospheric Research, Boulder, Colo, USA, 1996.

[33] A. A. M. Holtslag, E. I. F. De Bruijn, and H. L. Pan, "A high resolution air mass transformation model for short-range weather forecasting," Monthly Weather Review, vol. 118, no. 8, pp. 1561-1575, 1990.

[34] R. E. Dickinson, A. Henderson-Sellers, and P. J. Kennedy, "Biosphere-Atmosphere Transfer Scheme (BATS) version $1 \mathrm{E}$ as coupled to the NCAR Community Climate Model," Technical Note NCAR/TN-387+STR, National Center for Atmospheric Research, Boulder, Colo, USA, 1993.

[35] X. Zeng, M. Zhao, and R. E. Dickinson, "Intercomparison of bulk aerodynamic algorithms for the computation of sea surface fluxes using TOGA COARE and TAO data," Journal of Climate, vol. 11, no. 10, pp. 2628-2644, 1998.

[36] J. M. Fritsch and C. F. Chappell, "Numerical prediction of convectively driven mesoscale pressure systems. Part I: convective parameterization," Journal of the Atmospheric Sciences, vol. 37, no. 8, pp. 1722-1733, 1980.

[37] J. S. Pal, E. E. Small, and E. A. B. Eltahir, "Simulation of regional-scale water and energy budgets: representation of subgrid cloud and precipitation processes within RegCM," Journal of Geophysical Research D, vol. 105, no. 24, pp. 29579 29594, 2000.

[38] B. Fontaine, P. Roucou, and S. Trzaska, "Atmospheric water cycle and moisture fluxes in the West African monsoon: mean annual cycles and relationship using NCEP/NCAR reanalysis," Geophysical Research Letters, vol. 30, Article ID 117, 4 pages, 2003.

[39] A. Giannini, "Mechanisms of climate change in the Semiarid African Sahel: The local view," Journal of Climate, vol. 23, pp. 743-756, 2010.

[40] G. H. Roe, “Orographic precipitation,” Annual Review of Earth and Planetary Sciences, vol. 33, pp. 645-671, 2005.

[41] F. Giorgi, C. Jones, and G. Asrar, "Addressing climate information needs at the regional level: the CORDEX framework," WMO Bulletin, vol. 58, pp. 175-183, 2009. 

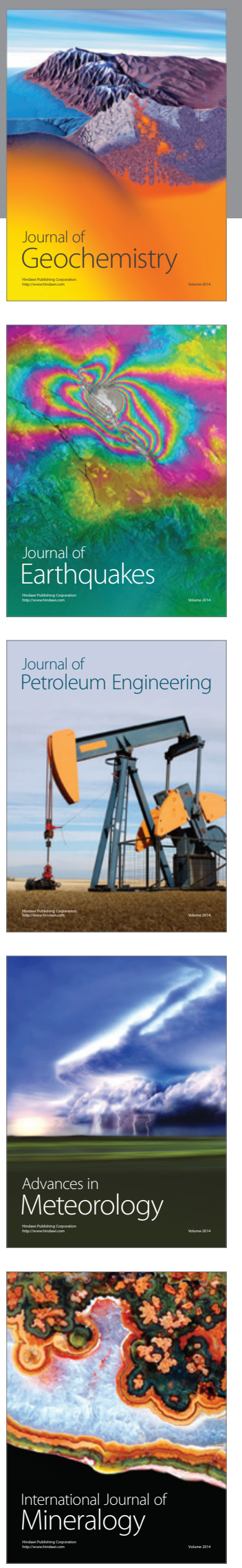
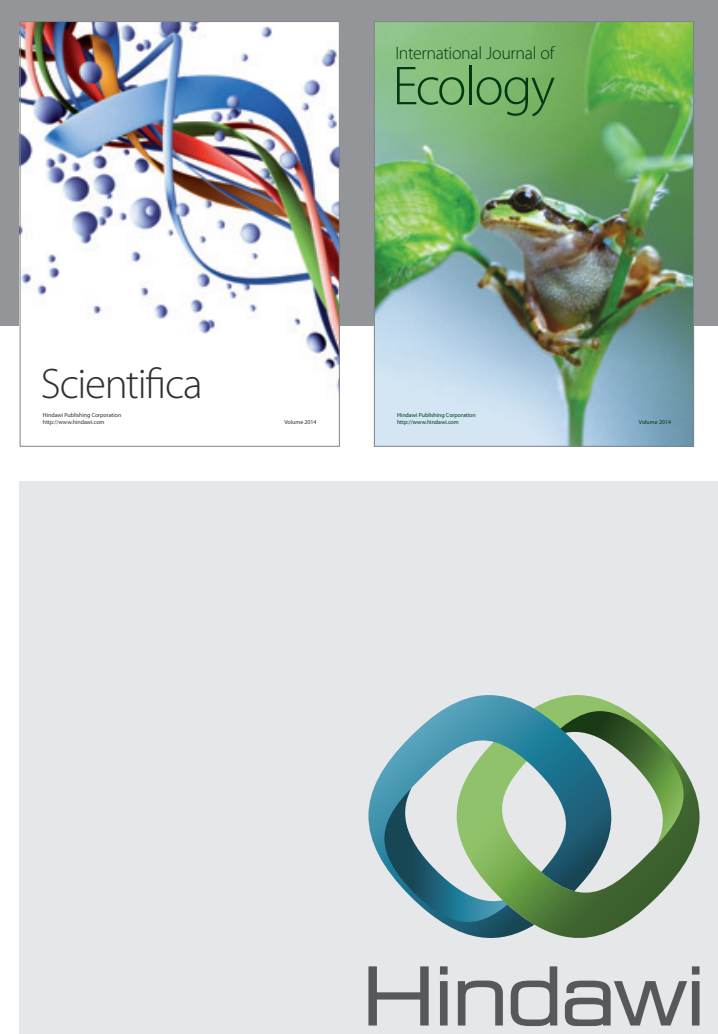

Submit your manuscripts at http://www.hindawi.com
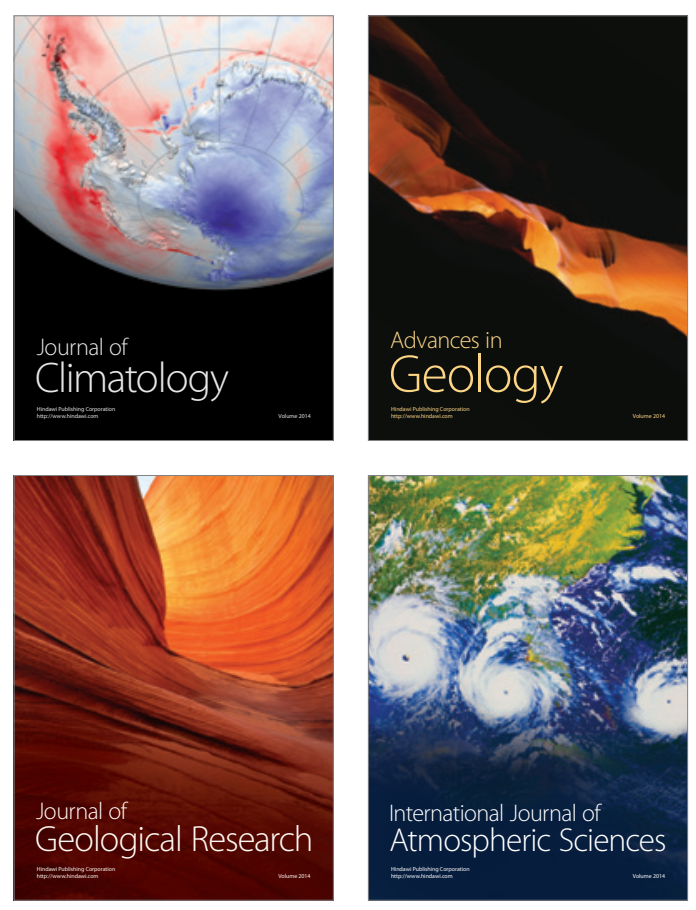
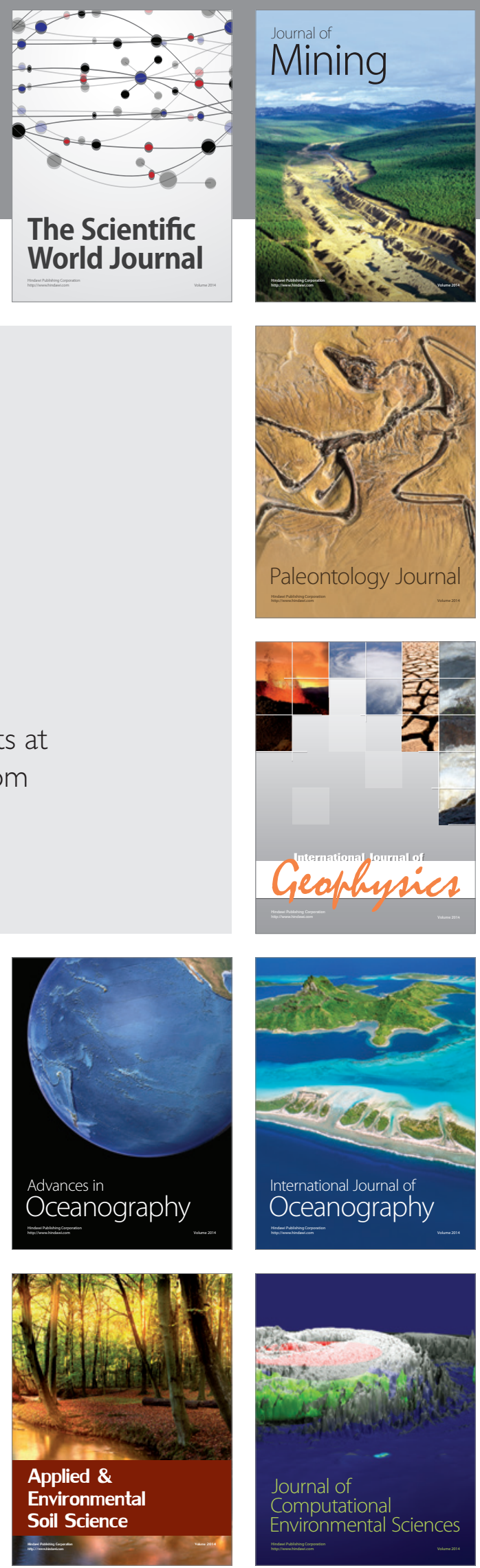